\title{
Effects of pore size, mesostructure and aluminum modification on FDU-12 supported NiMo catalysts for hydrodesulfurization
}

\author{
Pei Yuan ${ }^{1} \cdot$ Xue-Qin Lei $^{1} \cdot$ Hong-Ming Sun ${ }^{1} \cdot$ Hong-Wei Zhang $^{1} \cdot$ Chun-Sheng Cui ${ }^{2} \cdot$ Yuan-Yuan Yue $^{1} \cdot$ Hai-Yan Liu $^{2}$. \\ Xiao-Jun Bao ${ }^{1} \cdot$ Ting-Hai Wang $^{1}$
}

Received: 7 June 2020 / Published online: 1 September 2020

(c) The Author(s) 2020

\begin{abstract}
A series of NiMo/FDU-12 catalysts with tunable pore diameters and mesostructures have been controllably synthesized by adjusting the synthetic hydrothermal temperature and applied for the hydrodesulfurization of dibenzothiophene and its derivative. The state-of-the-art electron tomography revealed that the pore sizes of FDU-12 supports were enlarged with the increase in the hydrothermal temperature and the mesostructures were transformed from ordered cage-type pores to locally disordered channels. Meanwhile, the $\mathrm{MoS}_{2}$ morphology altered from small straight bar to semibending arc to spherical shape and finally to larger straight bar with the change of support structures. Among them, FDU-12 hydrothermally treated at $150{ }^{\circ} \mathrm{C}$ possessed appropriate pore diameter and connected pore structure and was favorable for the formation of highly active $\mathrm{MoS}_{2}$ with curved morphology; thus, its corresponding catalyst exhibited the best HDS activity. Furthermore, it was indicated that the isomerization pathway could be significantly improved for HDS of 4,6-dimethyldibenzothiophene after the addition of aluminum, which was expected to be applied to the removal of the macromolecular sulfur compounds. Our study sheds lights on the relationship between support effect, active sites morphology and HDS performance, and also provides a guidance for the development of highly active HDS catalysts.
\end{abstract}

Keywords Mesostructure $\cdot$ FDU-12 $\cdot$ NiMo catalysts $\cdot$ Hydrodesulfurization $\cdot$ Al modification

\section{Introduction}

Nowadays, the demand of low-sulfur, high-quality transportation fuels is growing rapidly by reason of the necessity to solve pollution problems induced by $\mathrm{SO}_{x}$ emissions

Handling Editor: Jian Liu

Edited by Xiu-Qiu Peng

Electronic supplementary material The online version of this article (https://doi.org/10.1007/s12182-020-00502-5) contains supplementary material, which is available to authorized users.

Ting-Hai Wang

wangth@fzu.edu.cn

1 National Engineering Research Center of Chemical Fertilizer Catalyst, School of Chemical Engineering, Fuzhou University, Fuzhou 350002, People's Republic of China

2 State Key Laboratory of Heavy Oil Processing, China University of Petroleum, Beijing 102249, People's Republic of China and to meet the increasingly stringent environmental protection laws and regulations (Rajendran et al. 2020). The main industrial processes to realize sulfur removal include hydrodesulfurization (HDS), oxidative desulfurization (Zhang et al. 2020; Wu et al. 2020; Wei et al. 2020; Jiang et al. 2020) and adsorptive desulfurization (Dong et al. 2020; Liu et al. 2019; Wu et al. 2018a; Li et al. 2018a). During the HDS process, catalysts play an important role in determining the efficiency. Therefore, the development of novel HDS catalysts with improved desulfurization efficiency has attracted ever-increasing attention and become a hot issue needed to be solved urgently.

Support is one of the most important parts for HDS catalyst, which plays a vital role in bearing active components, improving their dispersion as well as providing a space for the catalytic reactions. In addition, the support can affect the adsorption, diffusion and the accessibility of reactants to the active sites. Therefore, the properties of the support significantly influence the HDS catalytic activity. There are many tunable factors for support, such as composition, pore size and pore structure. Hence, the investigation of the influence 
of support structural characteristics on HDS performance is of great importance and is the foundation for guiding the development of highly active HDS catalysts.

In recent years, mesoporous materials with highly ordered pore structure, large pore volume and specific surface area have drawn increasing interests in the field of catalysis and exhibited advantageous performance in the removal of aromatic sulfide molecules. Different kinds of mesoporous materials have been applied as the supports of HDS catalysts, such as MCM (Kaluza et al. 2019; Mendez et al. 2017; Wang et al. 2005), HMS (Vutolkina et al. 2019; Palcheva et al. 2016), SBA (Wang et al. 2018; Thanh Tung and Qian 2018; Yuan et al. 2014) and KIT (Meng et al. 2020; Soni et al. 2010) series. The results showed that such supports favored the formation of type II active phases with good dispersion which exhibited higher HDS activity than $\gamma-\mathrm{Al}_{2} \mathrm{O}_{3}$ supported catalysts. Meanwhile, both the pore diameter and structure of catalyst supports showed important effects on the HDS activity (Zhou et al. 2020; Meng et al. 2020; Zhang et al. 2019). Song et al. (2016) synthesized a highly ordered cubic mesoporous silica material (SBA-16@ hexane) with a pore diameter of $15.1 \mathrm{~nm}$, the largest one among all the reported pore sizes of SBA-16 materials. The prepared catalyst NiMo/Al-SBA16@ hexane showed the highest HDS activity, which is attributed to the superior diffusivity of the novel SBA-16@ hexane with ultra-large pore size. Soni et al. (2010) reported that, compared to SBA-15 supported catalyst with a 2D hexagonal structure, NiMo/KIT-6 with a 3D bicontinuous structure exhibited a much higher HDS performance since the 3D mesostructured KIT- 6 could afford a better dispersion of active species and faster diffusion of reactants and products.

FDU-12 is a type of 3D mesoporous material with a cage-like face-centered cubic mesostructure which has been attracted increasing attention as supports for HDS in recent years (Hu et al. 2020; Meng et al. 2018; Wu et al. 2018b; Li et al. 2018b, 2019; Liu et al. 2016, 2017; Wang et al. 2017; Zhang et al. 2017; Du et al. 2016). For example, FDU-12based micro- and mesoporous composites (Wu et al. 2018b; Li et al. 2018b; Du et al. 2016), Ti- or Zr-modified FDU-12 (Meng et al. 2018; Cao et al. 2014), etc. were successively developed, showing a high HDS efficiency due to the appropriate synergistic effect of pore properties and acid property. However, FDU-12 has a cage-like structure with large cage pore size and small entrance size, which restricts the entry of the active metals and limits the utilization of the large pore. Meanwhile, the effect of FDU-12 structure on the morphology of the active phases and HDS activity have not been reported so far to the best of our knowledge.

In this work, a series of FDU-12 with different pore diameters and structures have been controllably synthesized by adjusting the hydrothermal temperature from 100 to $210^{\circ} \mathrm{C}$. The properties of corresponding NiMo supported catalysts are comprehensively characterized, and the effects of the pore size, mesostructure and aluminum modification on the $\mathrm{MoS}_{2}$ morphology and their catalytic performance for HDS are systematically explored. It is found that the morphology of the $\mathrm{MoS}_{2}$ active site changes with the change of the support structure, further affecting the HDS performance.

\section{Experimental section}

\subsection{Reagents}

Triblock copolymer poly(ethylene oxide)-poly(propylene oxide)-poly(ethylene oxide) F127 ( $\mathrm{PEO}_{106} \mathrm{PPO}_{70} \mathrm{PEO}_{106}$, $\mathrm{MW}=12,600$ ), tetraethyl orthosilicate (TEOS), 1,3,5-trimethylbenzene (TMB), potassium chloride $(\mathrm{KCl})$, hydrochloric acid $(\mathrm{HCl})$, aluminum isopropoxide, ammonium molybdate tetrahydrate and nickel nitrate hexahydrate were purchased from Sigma-Aldrich (USA). Dibenzothiophene (DBT) and 4,6-dimethyldibenzothiophene (4,6-DMDBT) were purchased from Adamas-beta (Switzerland). All the chemicals were used as received without further purification.

\subsection{Synthesis of supports}

\subsubsection{Preparation of FDU-12 supports with different structures}

The FDU-12 materials were synthesized according to the method reported previously with a minor modification (Yang et al. 2013). Firstly, F127 (2.0 g) and $\mathrm{KCl}(10.0 \mathrm{~g})$ were completely dissolved in $\mathrm{HCl}(2 \mathrm{M}, 120 \mathrm{~mL})$ at $15^{\circ} \mathrm{C}$; then, TMB (2.4 g) was added into the mixture and kept stirring for $6 \mathrm{~h}$. Afterward, TEOS (8.32 g) was added into the above mixture. After stirring for $24 \mathrm{~h}$ at $15{ }^{\circ} \mathrm{C}$, the mixtures were directly transferred into an autoclave for hydrothermal treatment at a given temperature $(100,130,150,170,190$ and $210{ }^{\circ} \mathrm{C}$ ) for $24 \mathrm{~h}$. The solid product was collected by filtration, washed with deionized water, dried and then calcined at $550{ }^{\circ} \mathrm{C}$ for $5 \mathrm{~h}$ to remove the templates. For convenience, the final samples were marked as F-( $T)$, in which $T$ represents the hydrothermal temperature.

\subsubsection{Preparation of the modified supports Al-FDU-12}

The support F-150 was selected to modify with aluminum by the post-synthesis method (Klimova et al. 2008). The catalysts were prepared as follows: $1.0 \mathrm{~g}$ of F-150 support was dissolved in $100 \mathrm{~mL}$ of dry ethanol containing the required amounts of aluminum isopropoxide the desired $\mathrm{Si} / \mathrm{Al}$ molar ratios of $100,60,40,30$ and 20 . This mixture was kept for $24 \mathrm{~h}$ at $60{ }^{\circ} \mathrm{C}$ with magnetic stirring. Then, the solid material was collected by a vacuum filtered device, washed several 
times with ethanol and deionized water to eliminate chloride anions. Finally, the sample dried at room temperature was calcined at $550{ }^{\circ} \mathrm{C}$ for $5 \mathrm{~h}$. The Al-modified materials are named as $\mathrm{Al}-\mathrm{F}(x)$, in which $x$ represents the theoretical $\mathrm{Si} /$ $\mathrm{Al}$ molar ratio.

\subsection{Catalyst preparation}

NiMo catalysts supported on $\mathrm{F}-(T)$ and $\mathrm{Al}-\mathrm{F}(x)$ were prepared by a standard incipient wetness co-impregnation technique reported elsewhere by using appropriate concentration of ammonium molybdate tetrahydrate and nickel nitrate hexahydrate as Mo and Ni sources, respectively. The nominal compositions of $\mathrm{MoO}_{3}$ and $\mathrm{NiO}$ in all prepared catalysts were $12 \mathrm{wt} \%$ and $3 \mathrm{wt} \%$, respectively, corresponding to the molar ratio of $\mathrm{Ni}: \mathrm{Mo}=3: 7$. After impregnation, the materials were dried at $80{ }^{\circ} \mathrm{C}$ for $12 \mathrm{~h}$ in an air atmosphere, followed by calcination at $500^{\circ} \mathrm{C}$ for $4 \mathrm{~h}$, denoted NiMo/F- $(T)$ and $\mathrm{NiMo} / \mathrm{Al}-\mathrm{F}(x)$, respectively.

\subsection{Catalyst characterization}

Small-angle X-ray scattering (SAXS) profiles of the support and corresponding catalysts were obtained from Bruker NanoSTAR with a 2-D detector and X-ray beam pinhole collimated $(40 \mathrm{kV}, 30 \mathrm{~mA})$. X-ray diffraction (XRD) experiments were collected on a Philips X'Pert diffractometer equipped with $\mathrm{Cu} \mathrm{K} \alpha$ radiation at a wavelength of $1.5406 \AA$ in the range of $2 \theta=8^{\circ}-70^{\circ} . \mathrm{N}_{2}$ adsorption-desorption isotherms were determined with a Micromeritics ASAP 2002 instrument (USA). The specific surface areas were calculated using the Brunauer-Emmett-Teller (BET) method. The samples to be measured were firstly degassed in the preparation station at $180^{\circ} \mathrm{C}$ with a vacuum of $10^{-5}$ Torr for $15 \mathrm{~h}$ and then switched to the analysis station for adsorption-desorption experiment at - $196{ }^{\circ} \mathrm{C}$. UV-Vis diffuse reflection spectroscopy (UV-Vis DRS) experiments were carried out on a Hitachi U-4100 UV-Vis spectrophotometer with the integration sphere diffuse reflectance attachment in the region of 200-800 nm. The standard support reflectance was used as the baseline for the corresponding catalyst measurement. Temperatureprogrammed reduction analyses with hydrogen $\left(\mathrm{H}_{2}-\mathrm{TPR}\right)$ for the oxidic catalysts were performed on a home-built apparatus. The sample $(100 \mathrm{mg})$ needed to be pretreated in an Ar stream at $450{ }^{\circ} \mathrm{C}$ for $2 \mathrm{~h}$ and then cooled down to room temperature. Then, the Ar flow was switched to a $10 \% \mathrm{H}_{2} / \mathrm{Ar}$ flow, and the sample was heated to $1000^{\circ} \mathrm{C}$ at a rate of $10{ }^{\circ} \mathrm{C} / \mathrm{min}$. Finally, the $\mathrm{H}_{2}$ consumption to reduce the metal oxides was detected by a thermal conductivity detector (TCD). Temperature-programmed desorption with ammonia $\left(\mathrm{NH}_{3}\right.$-TPD) measurements using the same apparatus described for the $\mathrm{H}_{2}$-TPR experiments. Firstly, the sample $(100 \mathrm{mg})$ was heated in a pure $\mathrm{He}$ flow from room temperature to $600{ }^{\circ} \mathrm{C}$ at a rate of $10{ }^{\circ} \mathrm{C} / \mathrm{min}$ and then cooled to $100{ }^{\circ} \mathrm{C}$. Secondly, $\mathrm{NH}_{3}$ was adsorbed for $20 \mathrm{~min}$, and the sample was subsequently purged by a flowing $\mathrm{He}$ stream to remove excessive and physically adsorbed $\mathrm{NH}_{3}$ at $100{ }^{\circ} \mathrm{C}$ for $1 \mathrm{~h}$. Thirdly, the sample was heated to $600{ }^{\circ} \mathrm{C}$ at a rate of $10^{\circ} \mathrm{C} / \mathrm{min}$ in a pure He flow and desorption pattern was recorded. Pyridine FT-IR adsorption experiments were measured on self-supported wafers in an in situ cell. The samples were dehydrated at $500{ }^{\circ} \mathrm{C}$ for $5 \mathrm{~h}$ under a vacuum of $1.33 \times 10^{-3} \mathrm{~Pa}$ followed by the adsorption of pure pyridine vapor at room temperature for $20 \mathrm{~min}$. The system was evacuated at 200 and $350{ }^{\circ} \mathrm{C}$, respectively, to record FTIR spectra. $\mathrm{X}$-ray photoelectron spectroscopy (XPS) was carried out on a VG ESCA Lab 250 spectrometer using $\mathrm{Al} \mathrm{K} \alpha$ radiation for the sulfided catalysts. C1s of adventitious carbon $(285.0 \mathrm{eV})$ was used as reference to calibrate all binding energies (BE), and the obtained XPS spectra were fitted by using XPSPEAK software in order to quantify the contents of Mo and Ni species. Highresolution transmission electron microscopy (HRTEM) was obtained on a Philips Tecnai G2 F20 transmission electron microscope operated at an accelerating voltage of $200 \mathrm{kV}$, and the images were recorded on a TVIPS $1 \mathrm{k} \times 1 \mathrm{k} C \mathrm{CD}$ camera.

\subsection{Catalytic activity}

Prior to the catalytic activity testing, the catalysts were firstly presulfided for $3 \mathrm{~h}$ at $360{ }^{\circ} \mathrm{C}$ by using $\mathrm{CS}_{2}(3 \mathrm{wt} \%)$ in cyclohexane. The HDS activity was evaluated in a continuously flowing tubular fixed-bed microreactor with the internal diameter of $10.0 \mathrm{~mm}$ and length of $500 \mathrm{~mm}$. The assessment condition is $360^{\circ} \mathrm{C}$ for NiMo/F- $(T)$ and $340{ }^{\circ} \mathrm{C}$ for NiMo/Al-F $(x)$ with the liquid hourly space velocity (LHSV) of $20 \mathrm{1} / \mathrm{h}$, total pressure of $4.0 \mathrm{MPa}$ and $\mathrm{H}_{2} / \mathrm{hydro}-$ carbon volumetric ratio of $300.1 \mathrm{wt} \% \mathrm{DBT} / 4,6-\mathrm{DMDBT}$ in heptane was used as a model compound. The catalyst $(0.5 \mathrm{~g})$ was diluted to a constant volume of $2.0 \mathrm{~mL}$ by using quartz particles $(0.25 \mathrm{~mm})$ before being put into the reactor. After the reaction was stabilized for $4 \mathrm{~h}$, the products were collected and the sulfur content of original solution and products was analyzed by a WK-2C-type microcoulomb meter. The products were analyzed by an offline Finnigan Trace GC/MS instrument installed with an HP-5MS capillary column $(30 \mathrm{~m} \times 0.25 \mathrm{~mm} \times 0.25 \mu \mathrm{m})$ and a pulsed flame photometric detector (O. I. Co., PFPD 5380).

Assuming that the HDS reaction of DBT is a quasifirst-order reaction, the HDS activity of the catalyst can be obtained from the following formula (Klimova et al. 2008):

$k_{\mathrm{HDS}}=\frac{F}{m} \ln \left(\frac{1}{1-\tau}\right)$

where $F$ is the number of moles of DBT entering the reactor per second, unit $\mathrm{mol} / \mathrm{s} ; m$ is the loading mass of the catalyst, unit $\mathrm{g} ; \tau$ is the total conversion of DBT hydrodesulfurization; and $k_{\mathrm{HDS}}$ is the HDS reaction rate constant, unit $\mathrm{mol} / \mathrm{g} \cdot \mathrm{s}$. 


\section{Results and discussion}

\subsection{Characterization of F-( $T$ ) supports and corresponding NiMo catalysts}

FDU-(T) supports prepared with different hydrothermal temperatures were characterized by the SAXS and $\mathrm{N}_{2}$ sorption, and the results are displayed in Fig. S1. Five well-resolved diffraction peaks assigned to the 111, 220, 311, 420, 511 and 531 reflections can be clearly observed in F-100 support

Table 1 Textural properties of the supports F- $(T)$ and corresponding NiMo catalysts with different hydrothermal temperatures

\begin{tabular}{llllll}
\hline Sample & $S_{\text {BET }}, \mathrm{m}^{2} / \mathrm{g}^{\mathrm{a}}$ & $V_{\mathrm{t}}, \mathrm{ml} / \mathrm{g}^{\mathrm{b}}$ & $P_{\mathrm{a}}, \mathrm{nm}^{\mathrm{c}}$ & $P_{\mathrm{d}}, \mathrm{nm}^{\mathrm{d}}$ & $A_{0}, \mathrm{~nm}^{\mathrm{e}}$ \\
\hline F-100 & 541.1 & 0.42 & 10.8 & $<3$ & 35.6 \\
F-130 & 462.6 & 0.83 & 17.2 & $<3$ & 36.1 \\
F-150 & 357.9 & 0.92 & 17.4 & 8.8 & 36.8 \\
F-170 & 264.3 & 0.95 & 17.9 & 10.6 & 37.5 \\
F-190 & 246.9 & 0.96 & 23.1 & 13.2 & 39.3 \\
F-210 & 224.2 & 1.03 & 26.5 & 18.1 & 39.6 \\
NiMo/F-100 & 481.9 & 0.39 & 10.5 & $<3$ & 27.8 \\
NiMo/F-130 & 397.6 & 0.78 & 16.9 & $<3$ & 35.4 \\
NiMo/F-150 & 288.4 & 0.82 & 17.2 & 8.5 & 36.4 \\
NiMo/F-170 & 213.7 & 0.84 & 17.7 & 10.5 & 37.4 \\
NiMo/F-190 & 207.9 & 0.87 & 22.8 & 12.7 & 39.1 \\
NiMo/F-210 & 182.7 & 0.90 & 26.0 & 17.6 & 39.2 \\
\hline
\end{tabular}

${ }^{a}$ BET surface area

${ }^{\text {b}}$ Pore volume

${ }^{\text {c}}$ Pore size obtained by adsorption branch

${ }^{\mathrm{d}}$ Entrance size obtained by desorption branch

${ }^{\mathrm{e}}$ Unit cell parameter, the value is calculated by $a_{0}=d_{111} \times \sqrt{3}$ and $d_{111}$ is determined by the first scattering peak of SAXS pattern

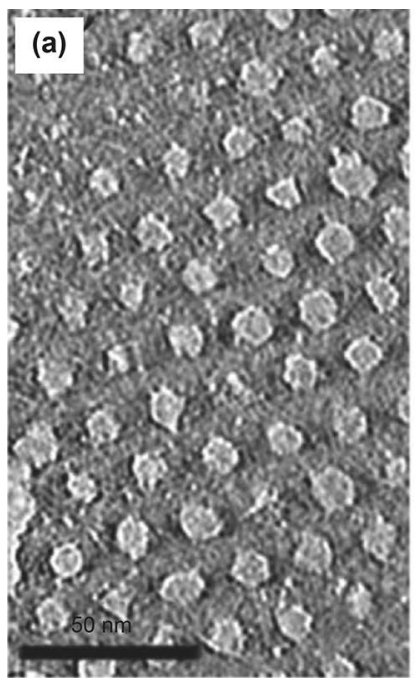

(Fig. S1a), indicating highly ordered large cage-type $\mathrm{Fm} 3 \mathrm{~m}$ mesoporous silica FDU-12 has been successfully synthesized (Yu et al. 2006). Although some of the diffraction peaks disappear with further increase in the hydrothermal temperature from 100 to $210{ }^{\circ} \mathrm{C}$, the primary diffraction peaks indexed as 111, 220 and 311 are always present, indicating the preservation of the ordered mesostructure. It is found that the 111 diffraction peak gradually shifts to lower $q$ value with the increase in the hydrothermal temperature, and accordingly, the unit cell parameters $\left(a_{0}\right)$ increase from 35.6 to $39.6 \mathrm{~nm}$ (Table 1). Figure $\mathrm{S} 1 \mathrm{~b}$ shows the $\mathrm{N}_{2}$ adsorption-desorption isotherms of FDU-( $T)$ supports, and they all exhibit type IV isotherm. However, the shape of hysteresis loop changes from $\mathrm{H} 2$ to $\mathrm{H} 1$ (F-210) as increasing the hydrothermal temperature, indicating that the structure of FDU-(T) supports may transforms from 3D to 2D or to analogous 2D. Figures S1c and 1d give the pore size and entrance size distribution curves of FDU-( $T$ ) supports calculated from the adsorption and desorption branch isotherms, respectively. The entrance sizes of F-100 and F-130 supports are less than $3 \mathrm{~nm}$, implying that the pores are rarely connected or even partially isolated. With the increase in the hydrothermal temperature from $150{ }^{\circ} \mathrm{C}$ to $190{ }^{\circ} \mathrm{C}$, the pore sizes increase from 17.4 to $23.1 \mathrm{~nm}$ and the entrance sizes increase from 8.8 to $13.2 \mathrm{~nm}$, indicating the pore connection is more full. The pore size $(26.5 \mathrm{~nm})$ and the entrance size $(18.1 \mathrm{~nm})$ of F-210 support are gradually approaching with further increase in the hydrothermal temperature and the entrance of the cage-type hole is mutually linked completely, suggesting the support structure has been transformed to homologous 2D straight channel.

Figure 1 shows the electron tomography slice images of the supports under different hydrothermal temperatures. The results indicate that the supports (F-100 and F-130) obtained
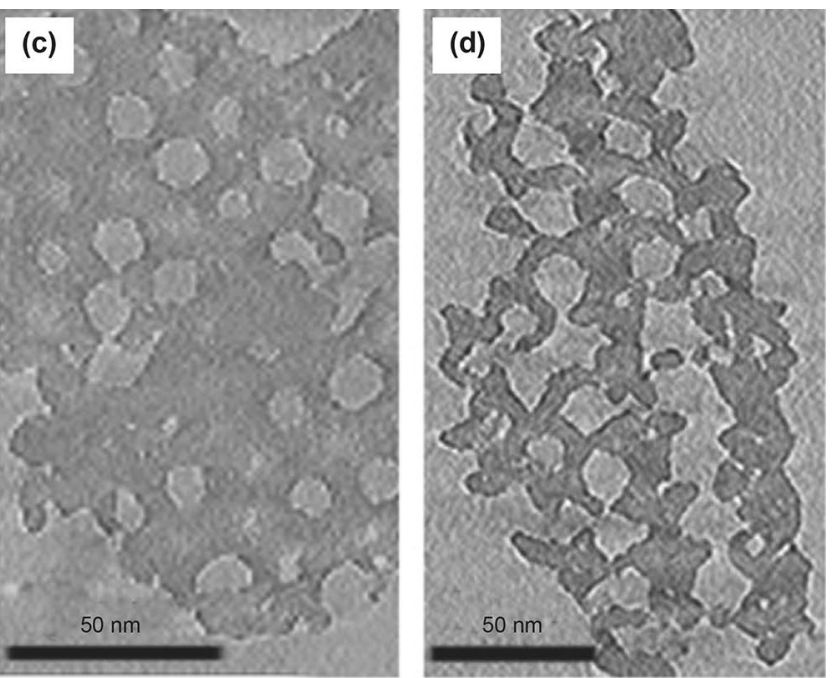

Fig. 1 Electron tomography slice images of F-100 (a), F-130 (b), F-150 (c), F-190 (d) 
at lower hydrothermal temperature have relatively independent cage-type holes with small connection in between, while the shape of cavity is relatively regular. As the hydrothermal temperature increases (F-150), the cavity size and window aperture increase significantly, and the cage-type holes are connected by a larger window. With the hydrothermal temperature further increases to $190{ }^{\circ} \mathrm{C}$, the cavity and entrance sizes of the support are gradually approaching, while the cages are interpenetrated, which accords well with the $\mathrm{N}_{2}$ sorption results, indicating that suitable hydrothermal temperature can effectively improve the cavity and entrance size.

The SAXS patterns, $\mathrm{N}_{2}$ adsorption-desorption isotherms and pore size distribution of NiMo/F- $(T)$ catalysts are presented in Fig. 2. The SAXS patterns (Fig. 2a) of NiMo/F$(T)$ catalysts all exhibit two or three well-resolved peaks which are the characteristic of FDU-12 materials, suggesting that ordered large cage-type structure is maintained in all catalysts after deposition of $\mathrm{Ni}$ and Mo species. The $\mathrm{N}_{2}$ adsorption-desorption isotherms of NiMo/F- $(T)$ catalysts (Fig. 2b) all correspond to a type IV, and the shape of hysteresis loop is almost unchanged after impregnation of NiMo species. In addition, the position of the capillary condensation is shifted to higher $P / P_{0}$ as the rise of hydrothermal temperature, implying the enlargement of the pore size, which is confirmed by the pore size and entrance size distribution curves calculated from adsorption (Fig. 2c) and desorption branches (Fig. 2d) of NiMo/F- $(T)$ catalysts, respectively.

The textural and structural characteristics (specific surface area $S_{\mathrm{BET}}$, pore volume $V_{\mathrm{P}}$, pore size, entrance size and unit cell parameter $a_{0}$ ) of FDU-(T) supports and corresponding catalysts are summarized in Table 1 . It can be observed that the specific surface areas of FDU-(T) supports decrease, and the pore volumes, pore sizes and entrance sizes increase gradually with an increase in the hydrothermal treatment temperature. The specific surface area of F-210 support $\left(224.2 \mathrm{~m}^{2} / \mathrm{g}\right)$ is less than half of F-100 support $\left(541.1 \mathrm{~m}^{2} / \mathrm{g}\right)$; (a)

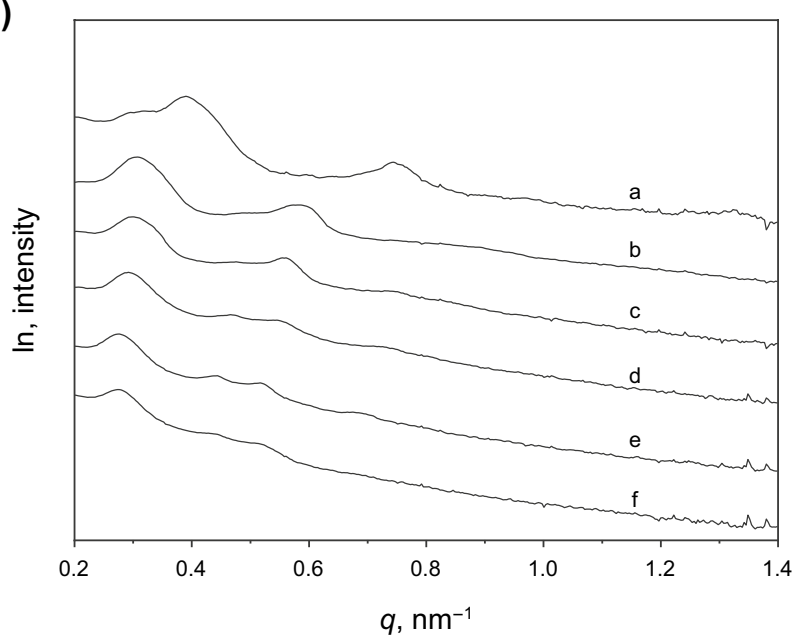

(c)

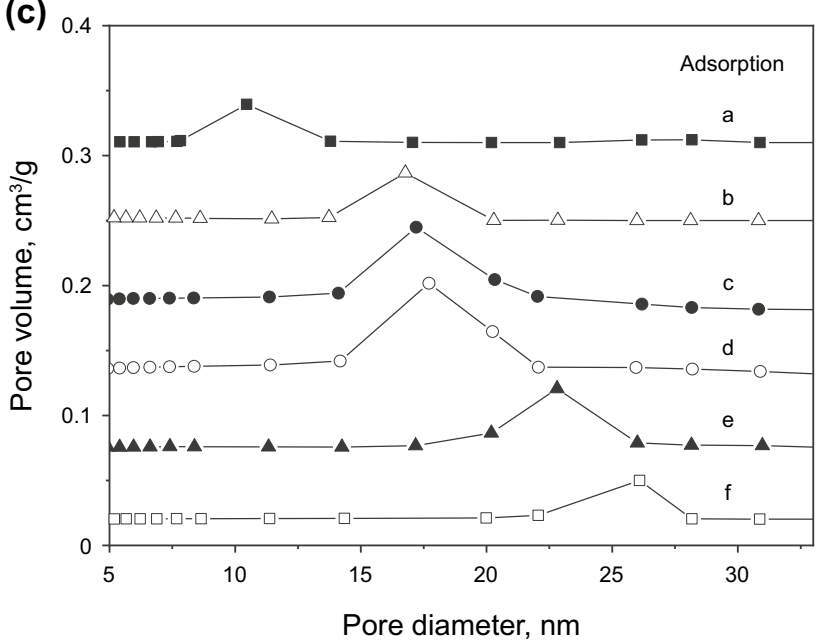

(b)

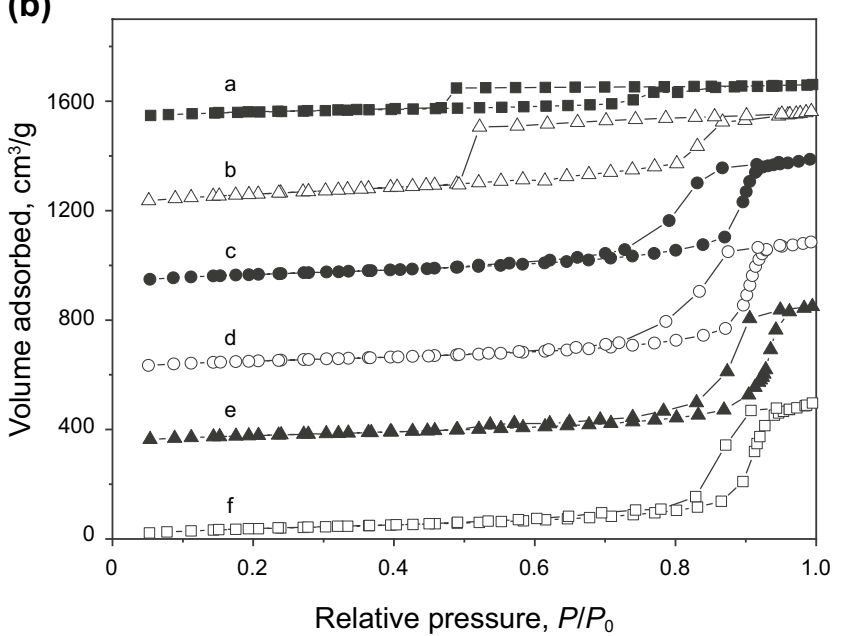

(d)

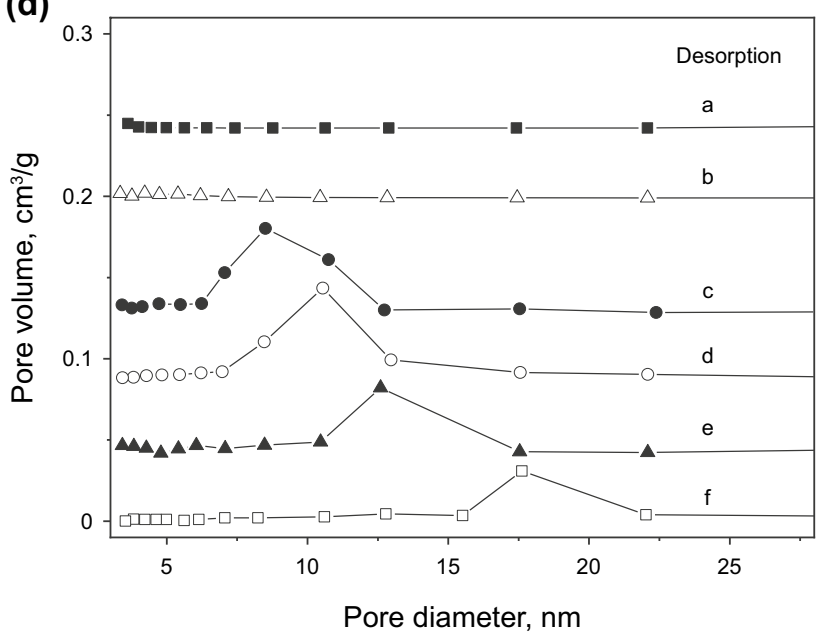

Fig. 2 SAXS patterns (a), $\mathrm{N}_{2}$ adsorption-desorption isotherms (b), pore size distribution curves calculated from adsorption (c) and desorption branches (d) of the catalysts NiMo/F-100 (a), NiMo/F-130 (b), NiMo/F-150 (c), NiMo/F-170 (d), NiMo/F-190 (e) and NiMo/F-210 (f) 
nevertheless, the pore size and entrance size of the former $(26.5 \mathrm{~nm}$ and $18.1 \mathrm{~nm})$ are over twice and six times as large as the latter $(10.8 \mathrm{~nm}$ and $<3 \mathrm{~nm})$, respectively. F127 is one of the most studied amphiphilic surfactants that are commonly used as a template for synthesizing mesoporous materials, and it is believed that F127 can drive the formation of micelles in which the hydrophobic PPO blocks can act as the core and the hydrophilic PEO blocks as the corona (Mayanovic et al. 2014). It has been known that the hydrophilicity of the PEO blocks decreases with increased hydrothermal temperature and PEO blocks can be drawn back into the micelles which increases the hydrophobic segment volume of block copolymer micelles, consequently resulting in the enlargement of the pore size and entrance size and the concomitant decline of the surface area. Compared to FDU- $(T)$ supports, the structural parameters of NiMo/F- $(T)$ catalysts are all slightly decreased, which should be related to the increase in the samples' density after incorporation of $\mathrm{Ni}$ and Mo precursors or due to some blockage of pores (Wang et al. 2005).

Figure 3a shows the powder XRD patterns of NiMo/F$(T)$ catalysts, and they all present a very broad peak at around $23^{\circ}$ which is typical for amorphous silica (Cao et al. 2014). It can be seen that no signal of any crystalline phase is detected in NiMo/F-100 and NiMo/F-130 catalysts, suggesting that the metallic particles are well dispersed on the surface of the supports with high specific surface areas (Wang et al. 2002). However, weak diffraction peaks are observed for $\mathrm{NiMo} / \mathrm{F}-150$ catalyst at around $26.7^{\circ}$, which are corresponding to the reflections of $\mathrm{MoO}_{3}$ in orthorhombic phase (JCPDS No. 09-0209). Furthermore, the intensity of $\mathrm{MoO}_{3}$ diffraction gradually strengthens with the decline of the specific surface areas, indicating the dispersion of active particles decreases for NiMo supported catalysts. The active components with the same loading amount are easier to aggregate in the supports with lower specific surface areas and form large oxide particles after the high-temperature calcination.

To discern the chemical state and obtain more information about the dispersion of Mo species in NiMo/F(T) catalysts, UV-Vis DRS spectra were recorded after subtracting the spectra of the corresponding supports as displayed in Fig. 3b. The adsorption bands represent the ligand-to-metal charge transfer $\mathrm{O}^{2-} \rightarrow \mathrm{Mo}^{6+}$, and the exact positions of these bands are affected by the aggregation and coordination state of the $\mathrm{Mo}^{6+}$ species. The isolated molybdate species in tetrahedral coordination, $\operatorname{Mo}\left(T_{\mathrm{d}}\right)$, show a characteristic absorption band at $\sim 230 \mathrm{~nm}$, whereas polymolybdate octahedral $\operatorname{Mo}\left(O_{\mathrm{h}}\right)$ species absorb at 280-320 nm depending on the aggregation degree of these species (Weber 1995). As shown in the spectra (Fig. 3b), a mixture of Mo species in tetrahedral and octahedral coordination is present in all $\mathrm{NiMo} / \mathrm{F}-(T)$ catalysts, but the Mo absorption edges produce a slight red shift with increased hydrothermal temperature, indicating the occurrence of larger $\mathrm{MoO}_{3}$ clusters, which is in agreement with the XRD result (Fig. 3a).

To further compare the degree of sulfidation and the dispersion of metal species on the surface of FDU-( $T$ ) supports, the freshly sulfided catalysts were characterized by XPS. The Mo $3 d$ XPS spectra of NiMo/F- $(T)$ catalysts containing the peaks of $\mathrm{S} 2 s$ and three Mo $3 d$ doublets were deconvoluted as shown in Fig. S2. Mo signals were fitted considering doublets (corresponding to Mo $3 d_{5 / 2}$ and Mo $3 d_{3 / 2}$ contributions) originated from $\mathrm{Mo}^{6+}$ (oxidic molybdenum) with the binding energies at 232.3 and $235.4 \mathrm{eV}, \mathrm{Mo}^{5+}$ (oxysulfide
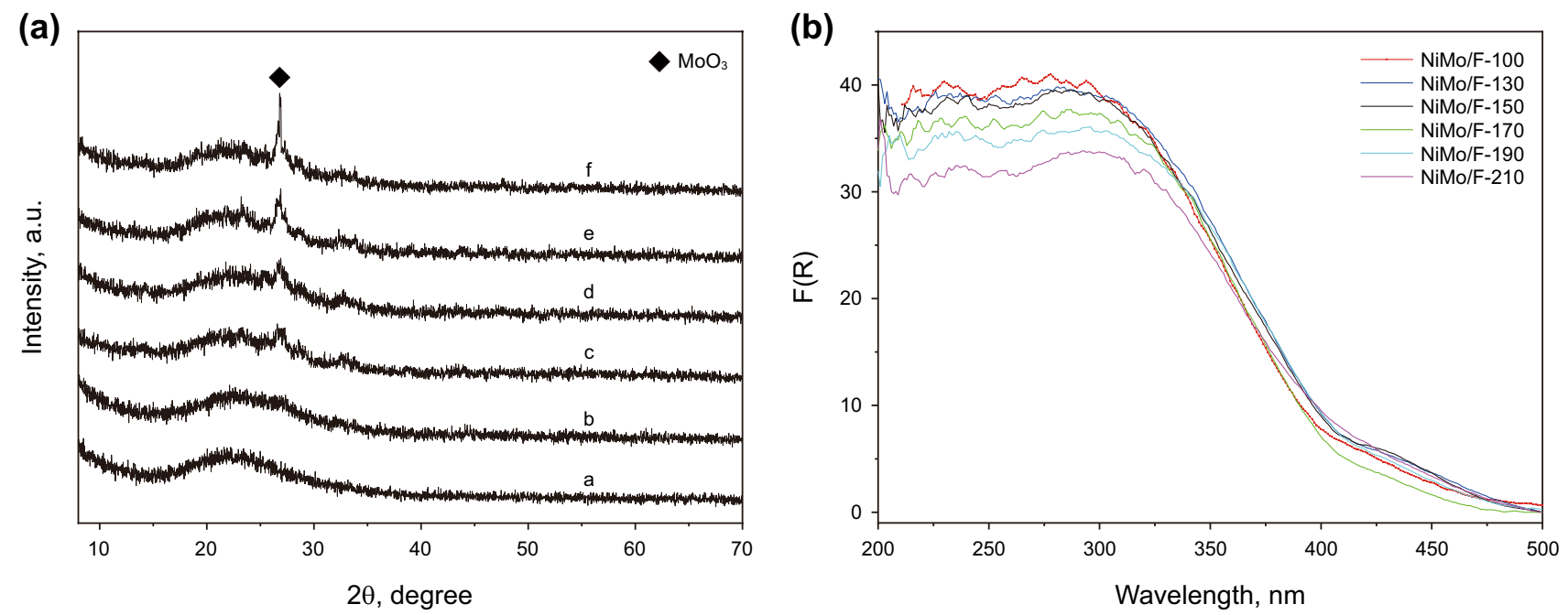

Fig. 3 XRD patterns (a) and UV-Vis DRS spectra (b) of the NiMo/F-(T) catalysts: NiMo/F-100 (a), NiMo/F-130 (b), NiMo/F-150 (c), $\mathrm{NiMo} / \mathrm{F}-170(\mathbf{d}), \mathrm{NiMo} / \mathrm{F}-190(\mathbf{e})$ and $\mathrm{NiMo} / \mathrm{F}-210(\mathbf{f})$ 
species) with the binding energies at 230.1 and $233.2 \mathrm{eV}$ and $\mathrm{Mo}^{4+}$ (corresponding to $\mathrm{MoS}_{2}$ ) with the binding energies at 228.4 and $231.5 \mathrm{eV}$. Moreover, S $2 s$ level which the binding energy is at about $225.9 \mathrm{eV}$ in the spectra must be subtracted from the total spectra of Mo $3 d$ in the concentration calculation of the different Mo species (Escobar et al. 2009). The sulfidation degree of Mo species, $\mathrm{Mo}_{\text {sulfidation, }}$, is expressed as the ratio of $\mathrm{Mo}^{4+} / \mathrm{M}_{\mathrm{TOT}}\left(\mathrm{M}_{\mathrm{TOT}}=\mathrm{Mo}^{4+}+\mathrm{Mo}^{5+}+\mathrm{Mo}^{6+}\right)(\mathrm{Gao}$ et al. 2018; Han et al. 2012), and the corresponding results are given in Table 2. It is shown that the highest sulfidation degree is obtained from the NiMo/F-100 catalyst (51.3\%). When the $T$ is 150 , the $\mathrm{Mo}_{\text {sulfidation }}$ of the corresponding catalyst generates only a slight drop to $49.0 \%$. However, further increase in the hydrothermal temperature results in a rapid decline of the sulfidation degree. It is decreased to $38.4 \%$ for the NiMo/F-210 catalyst probably owing to the formation of bulk $\mathrm{MoO}_{3}$ crystallites.

The surface $\mathrm{Ni} /(\mathrm{Ni}+\mathrm{Mo})$ and $\mathrm{S} / \mathrm{Mo}$ atomic ratios were also determined by XPS and the results are given in Table 2 . The NiMo catalysts correspond to theoretical $\mathrm{Ni} /(\mathrm{Ni}+\mathrm{Mo})$ atomic ratio of 0.3 and S/Mo atomic ratio of 2. In our experiment, the experimental $\mathrm{Ni} /(\mathrm{Ni}+\mathrm{Mo})$ and $\mathrm{S} / \mathrm{Mo}$ atomic ratios at lower hydrothermal temperature $\left(100\right.$ and $\left.130{ }^{\circ} \mathrm{C}\right)$ are almost around the theoretical value, indicating that $\mathrm{Ni}$ is evenly dispersed on the surface of catalysts. However, experimental $\mathrm{Ni} /(\mathrm{Ni}+\mathrm{Mo})$ and $\mathrm{S} / \mathrm{Mo}$ atomic ratios of the catalysts NiMo/F-190 and NiMo/F-210 gravely deviate from the theoretical value due to the poor dispersion of Mo species.

The Ni $2 p$ XPS spectra of the sulfided NiMo/FDU-12 catalysts are presented in Fig. S3, and the Ni $2 p$ envelope is decomposed by considering three major contributions corresponding to $\mathrm{NiS}_{x}$ sulfided phase (which could arise from $\mathrm{Ni}_{2} \mathrm{~S}_{3}, \mathrm{Ni}_{9} \mathrm{~S}_{8}$ or NiS, with binding energy between 853.5 and $853.8 \mathrm{eV}$ ), $\mathrm{NiO}_{x}$ (binding energy of $856.9 \mathrm{eV}$ ) and the

Table 2 XPS parameters of the different contributions Mo $3 d$ and Ni $2 p$ obtained for sulfided $\mathrm{NiMo} / \mathrm{F}-(T)$ catalysts

\begin{tabular}{llllll}
\hline Catalyst & $\mathrm{Mo}_{\text {sulfidation }}^{\mathrm{a}}$ & $\mathrm{PR}^{\mathrm{b}}$ & $(\mathrm{Ni} / \mathrm{Mo})_{\text {slabs }}^{\mathrm{c}}$ & $\mathrm{S}^{\mathrm{Mo}}{ }^{\mathrm{d}}$ & $\begin{array}{l}\mathrm{Ni} / \\
(\mathrm{Ni}+\mathrm{Mo})^{\mathrm{d}}\end{array}$ \\
\hline $\mathrm{NiMo} / \mathrm{F}-100$ & 51.3 & 38.9 & 0.21 & 2.0 & 0.29 \\
$\mathrm{NiMo} / \mathrm{F}-130$ & 50.6 & 38.2 & 0.20 & 1.8 & 0.28 \\
$\mathrm{NiMo} / \mathrm{F}-150$ & 49.0 & 36.1 & 0.18 & 1.7 & 0.26 \\
$\mathrm{NiMo} / \mathrm{F}-170$ & 46.4 & 32.5 & 0.15 & 1.5 & 0.23 \\
$\mathrm{NiMo} / \mathrm{F}-190$ & 42.8 & 28.7 & 0.12 & 1.3 & 0.19 \\
$\mathrm{NiMo} / \mathrm{F}-210$ & 38.4 & 23.4 & 0.09 & 1.1 & 0.14 \\
\hline
\end{tabular}

${ }^{\mathrm{a}} \mathrm{Mo}_{\text {sulfidation }}=\mathrm{Mo}^{4+} / \mathrm{M}_{\mathrm{TOT}} \times 100, \quad M_{\mathrm{TOT}} \quad$ (total surface molybdenum $)=\mathrm{Mo}^{4+}+\mathrm{Mo}^{5+}+\mathrm{Mo}^{6+}$

${ }^{\mathrm{b}} \mathrm{PR}=\mathrm{NiMoS} / \mathrm{Ni}_{\mathrm{T}} \times 100, \quad \mathrm{Ni}_{T} \quad$ (total surface $\mathrm{Ni})=\mathrm{NiS}_{x}+\mathrm{NiMoS}+\mathrm{NiO}_{x}$

${ }^{\mathrm{c}}(\mathrm{Ni} / \mathrm{Mo})_{\text {slabs }}=$ promoter ratio $=\mathrm{NiMoS} / \mathrm{Mo}^{4+}$

${ }^{\mathrm{d}}$ Atomic ratios determined by XPS analysis so-called NiMoS phase (with binding energy between 854.0 and $855.0 \mathrm{eV}$ ) (Ninh et al. 2011; Escobar et al. 2009). Two parameters of promotion rate (PR) and promoter ratio (see the corresponding formulas in the footnote of Table 2) are closely related to the formation of $\mathrm{NiMoS}$ active phases over the sulfided NiMo catalysts. The former represents the proportion of total deposited nickel that is actually engaged in the NiMoS phase formation; meanwhile, the latter is related to the amount of that highly active species (Cao et al. 2014; Merida-Robles et al. 1999). It is clear that the PR and (Ni/ Mo) $)_{\text {slabs }}$ values of NiMo/FDU-12 catalysts also decrease with the increase in the hydrothermal temperature, which consists with the changing trend of the $\mathrm{Mo}_{\text {sulfidation }}$ values.

HRTEM characterization of the sulfided NiMo/FDU$(T)$ catalysts was performed to obtain more information about the morphology and dispersion of $\mathrm{MoS}_{2}$ crystallites induced by the support structures. Representative micrographs selected for each one of the catalysts are shown in Fig. 4. The typical lattice fringes of $\mathrm{MoS}_{2}$ crystallites with a spacing of $0.61 \mathrm{~nm}$ (corresponds to the 002 interplanar distances) and some features of the FDU-12 mesopore structure are observed in micrographs of the sulfided catalysts (Cao et al. 2014). The straight $\mathrm{MoS}_{2}$ slabs are dispersed well over the sulfided NiMo/F-100 and NiMo/F-130 catalysts (Fig. 4a, b). With an increase in hydrothermal temperature, the entrance size of the support increases significantly and massive active phases migrate into the cage-like holes and form curved $\mathrm{MoS}_{2}$ crystallites (Fig. 4c) due to the confinement effect of the spherical pores. The entrance size and pore size of the supports further increase with the continue raise of the hydrothermal temperature ( $T=170$ and 190) and more active phases enter the cell. The curved $\mathrm{MoS}_{2}$ crystallites keep growing along with the eyeball until forming a closed-shell structure with a much more stacked arrangement and poor dispersion of $\mathrm{MoS}_{2}$ on NiMo/F-190 catalyst (Fig. 4e). The closed-shell $\mathrm{MoS}_{2}$ structure consists of slabs running all along the periphery of the unit cells, while a quite small proportion of flat slabs is detected inside the periphery region. With further increase in the hydrothermal temperature, the entrance size of the support enlarges obviously and approaches the cell size. The support structure transforms to homologous 2D straight channel and straight $\mathrm{MoS}_{2}$ slabs are formed on the NiMo/F-210 catalyst again (Fig. 4f).

From the above characterizations, the mesoporous material F-150 keeps ordered 3D cage-type structure with high specific surface area and large entrance size, and the corresponding NiMo catalyst shows relatively high $\mathrm{Mo}_{\text {sulfidation }}$, $\mathrm{PR}(\mathrm{Ni} / \mathrm{Mo})_{\text {slabs }}$ and better $\mathrm{MoS}_{2}$ morphology. Therefore, we chose F-150 as support to carry out Al modification with different molar ratios of $\mathrm{Si}: \mathrm{Al}$ by chemical grafting method and investigate the effect of alumina content on the HDS activity and selectivity of the corresponding NiMo catalysts. 

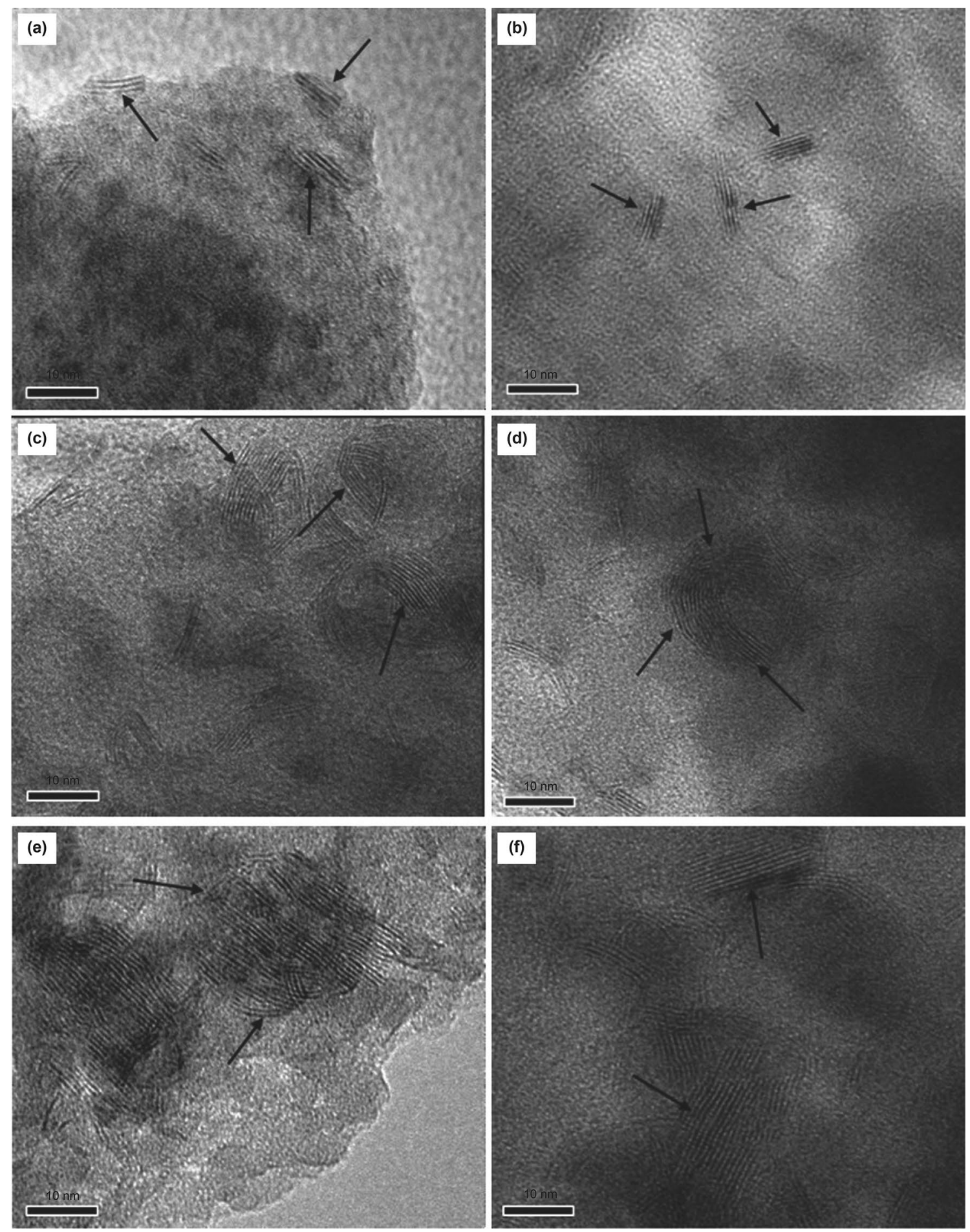

Fig. 4 HRTEM images of the sulfided catalysts: NiMo/F-100 (a), NiMo/F-130 (b), NiMo/F-150 (c), NiMo/F-170 (d), NiMo/F-190 (e) and $\mathrm{NiMo} / \mathrm{F}-210(\mathbf{f})$

\subsection{Characterization of $A \mathrm{I}-\mathrm{F}(\mathrm{x})$ supports and corresponding NiMo catalysts}

F-150 support was modified with different amounts of Al by using aluminum isopropoxide as alumina source through the post-synthesis method to obtain $\mathrm{Al}-\mathrm{F}(x)$ supports. Figure $\mathrm{S} 4$ shows the $\mathrm{N}_{2}$ adsorption-desorption isotherms of $\mathrm{Al}-\mathrm{F}(x)$ supports, and they all display a typical type IV isotherm with sharp inflection in the relative pressure range of 0.7-0.9. H2-type hysteresis loop confirms the ordered nature of the 
mesoporous F-150. No change is detected in the form of the isotherms or in the shape of the hysteresis loop, indicating the preservation of the support pore structure after Mo and $\mathrm{Ni}$ deposition (Fig. 5a). Analyzing from the adsorption and desorption branches of the isotherms, the maximum pore size and entrance size are located at $17.0 \mathrm{~nm}$ and $8.3 \mathrm{~nm}$, respectively (Fig. 5b, c). The parameters about surface areas, pore volumes, pore sizes and entrance sizes of NiMo/F-150 and NiMo/Al-F $(x)$ catalysts are given in Table 3. It can be observed that the alumination of $\mathrm{F}-150$ by reacting with $\mathrm{Al}^{3+}$ ions only leads to a slight drop in surface area and pore volume which might be attributed to the increase in the sample density after incorporation of aluminum (Klimova et al. 2008). This drop becomes more significant with the increase in the Al loading $(x=20)$ due to pore blockage caused by a low dispersion of the metal phases (Mo and $\mathrm{Ni}$ ). However, the pore sizes and entrance sizes do not suffer from a significant change after $\mathrm{Al}$ grafting.

In order to study the effect of incorporation of $\mathrm{Al}$ atoms on the dispersion of Mo and Ni species, powder XRD was performed and the results are displayed in Fig. 6a. As shown in the spectra, the intensity of the diffraction corresponding to reflections of $\mathrm{MoO}_{3}$ with orthorhombic phase (JCPDS No. 09-0209) decreases with the increase in the Al loading in the F-150 support, indicating the dispersion of the active components is improved. However, there is a peak located at $2 \theta=23.4^{\circ}$ whose intensity increases evidently with excess Al loading, implying the formation of aluminum molybdate $\mathrm{Al}_{2}\left(\mathrm{MoO}_{4}\right)_{3}$ (JCPDS No. 23-0764) in the NiMo/Al-F(20) catalyst. Klimova (Gutierrez-Alejandre et al. 2015) reported that part of excess extra-framework $\mathrm{Al}^{3+}$ species which were in the form of octahedral coordination was easy to form Anderson-type heteropolymolybdate and then transformed to $\mathrm{Al}_{2}\left(\mathrm{MoO}_{4}\right)_{3}$ after calcinations (Klimova et al. 2008). Therefore, $\mathrm{Al}$ incorporation in the $\mathrm{F}-150$ support, on the one hand, enhances the dispersion of Mo oxide species. On the other hand, it induces the formation of $\mathrm{Al}_{2}\left(\mathrm{MoO}_{4}\right)_{3}$. The DRS spectra of NiMo catalysts (Fig. 6b) show that Mo species in tetrahedral and octahedral coordination all present and also confirms the improved dispersion of Mo species with $\mathrm{Al}$ addition, and the $\mathrm{NiMo} / \mathrm{Al}-\mathrm{F}(x)$ catalysts produce a blue shift of the Mo absorption edge with decreasing $x$.

$\mathrm{H}_{2}$-TPR measurements of NiMo/F-150 and NiMo/Al$\mathrm{F}(x)$ catalysts were taken to explore the reducibility of the $\mathrm{Ni}$ and Mo species present in the oxidic precursors of the different catalysts (Fig. 6c). The reduction profiles of all the NiMo catalysts show hydrogen consumption in a broad temperature interval (between 300 and $900{ }^{\circ} \mathrm{C}$ ) with two areas along with many reduction peaks. The low-temperature peaks $\left(300-600{ }^{\circ} \mathrm{C}\right)$ can be attributed to the first-step reduction of polymeric octahedral Mo species from $\mathrm{Mo}^{6+}$ to $\mathrm{Mo}^{4+}$. The peaks at high temperature $\left(600-900{ }^{\circ} \mathrm{C}\right)$ can be ascribed to the second-step reduction from $\mathrm{Mo}^{4+}$ to $\mathrm{Mo}^{0}$ of
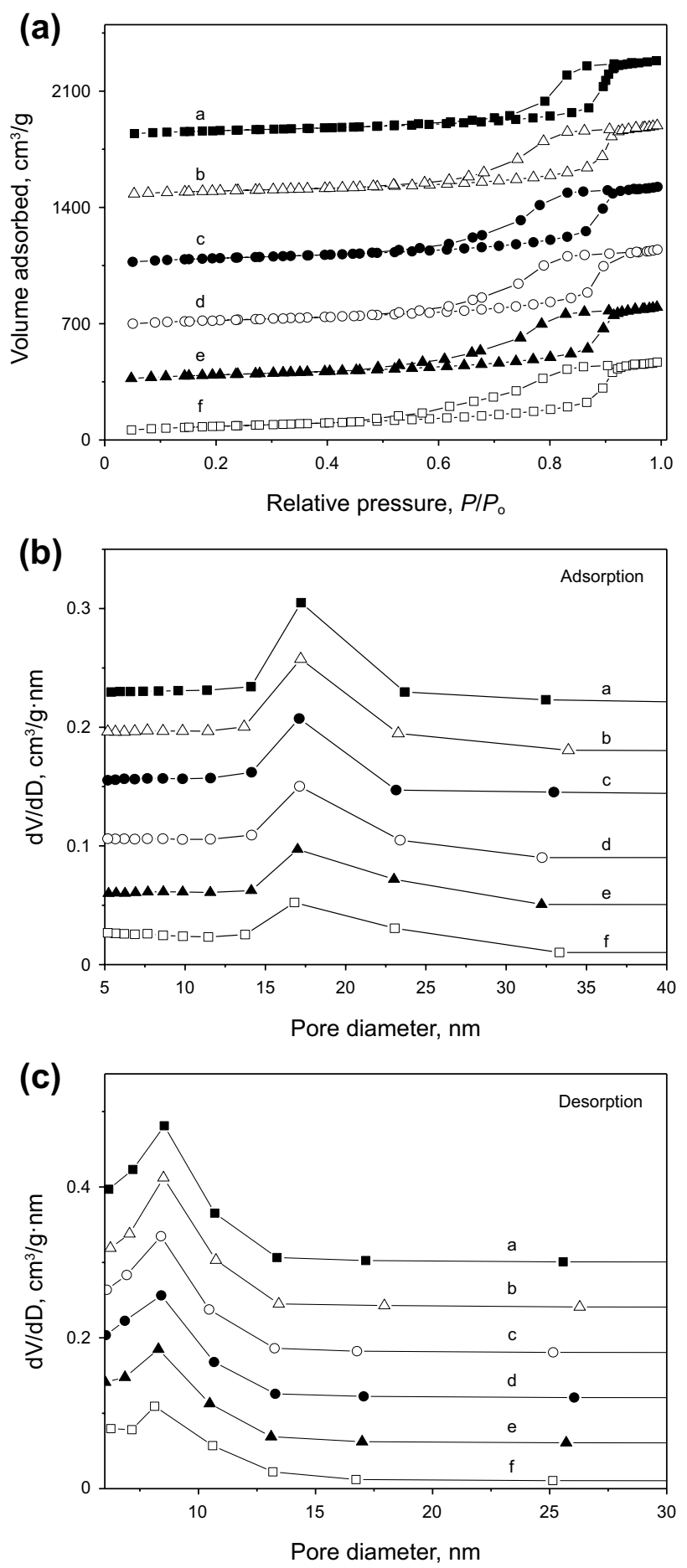

Fig. $5 \mathrm{~N}_{2}$ adsorption-desorption isotherms (a), pore size distribution curves calculated from adsorption (b) and desorption branches (c) of the catalysts: NiMo/Al-F(100) (a), NiMo/Al-F(60) (b), NiMo/ Al-F(40) (c), NiMo/Al-F(30) (d), NiMo/Al-F(20) (e)

the polymeric octahedral Mo species with different aggregation degrees and the reduction of tetrahedral Mo species from $\mathrm{Mo}^{6+}$ to $\mathrm{Mo}^{0}$ (Qu et al. 2003). It is observed that both the low- and high-temperature peaks shift to higher 
Table 3 Textural and structural characteristics of $\mathrm{Al}-\mathrm{F}(x)$ supports and corresponding catalysts

\begin{tabular}{lllll}
\hline Sample & $S_{\text {BET }}, \mathrm{m}^{2} / \mathrm{g}$ & $V_{\mathrm{t}}, \mathrm{ml} / \mathrm{g}$ & $P_{\mathrm{a}}, \mathrm{nm}$ & $P_{\mathrm{d}}, \mathrm{nm}$ \\
\hline Al-F(100) & 351.2 & 0.90 & 17.4 & 8.8 \\
Al-F(60) & 347.9 & 0.89 & 17.3 & 8.7 \\
Al-F(40) & 333.4 & 0.87 & 17.2 & 8.6 \\
Al-F(30) & 321.9 & 0.84 & 17.2 & 8.5 \\
Al-F(20) & 295.3 & 0.79 & 17.0 & 8.4 \\
NiMo/Al-F(100) & 274.6 & 0.81 & 17.2 & 8.5 \\
NiMo/Al-F(60) & 262.3 & 0.78 & 17.1 & 8.4 \\
NiMo/Al-F(40) & 253.7 & 0.75 & 17.0 & 8.3 \\
NiMo/Al-F(30) & 245.5 & 0.72 & 17.0 & 8.3 \\
NiMo/Al-F(20) & 204.8 & 0.65 & 16.8 & 8.1 \\
\hline
\end{tabular}
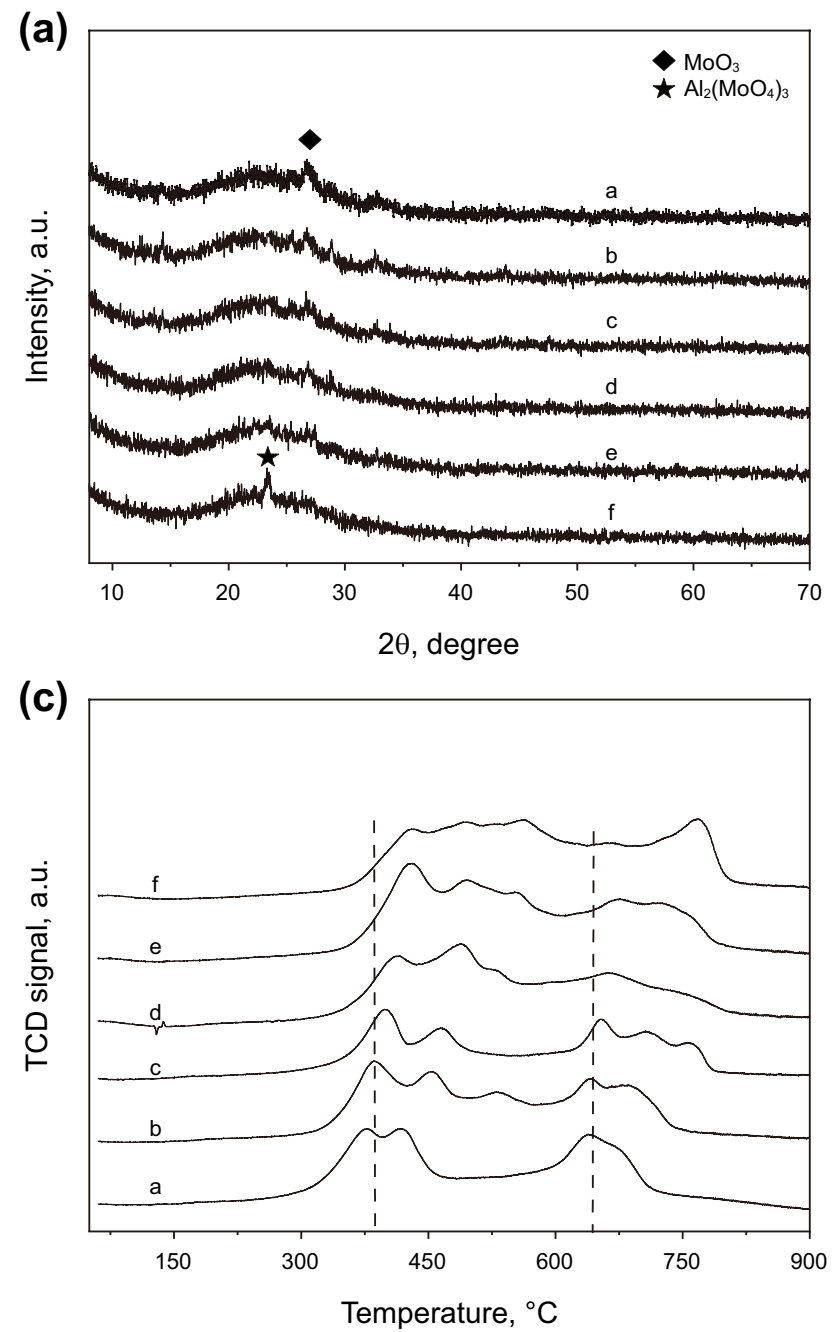

temperature with the decrease in the $\mathrm{Si} / \mathrm{Al}$ molar ratio, indicating the enhancement of the metal-support interaction after the incorporation of $\mathrm{Al}$.

The effect of Al modification on the acidity of catalysts was investigated by $\mathrm{NH}_{3}$-TPD (Fig. 6d) and pyridine FT-IR (Fig. S5). The strength of the acid sites can be determined by the desorption temperature of the adsorbed $\mathrm{NH}_{3}$. Based on the desorption temperature, the acid sites are classified as weak $\left(100-250{ }^{\circ} \mathrm{C}\right)$, medium $\left(250-400{ }^{\circ} \mathrm{C}\right)$ and strong $\left(T>400{ }^{\circ} \mathrm{C}\right)(\mathrm{Li}$ et al. 2012). It can be seen that all the catalysts display a broad peak in the temperature range from 75 to $400{ }^{\circ} \mathrm{C}$, revealing the presence of both weak and medium acid sites. In addition, the intensity of the desorption peaks shows that the number of acid sites in the NiMo/Al-F(100) catalyst is much higher than that in the NiMo/F-150 catalyst. Moreover, the increase in the $\mathrm{Al}$ content leads to a higher intensity of the desorption peaks, which means that Al modification can improve the acidity.
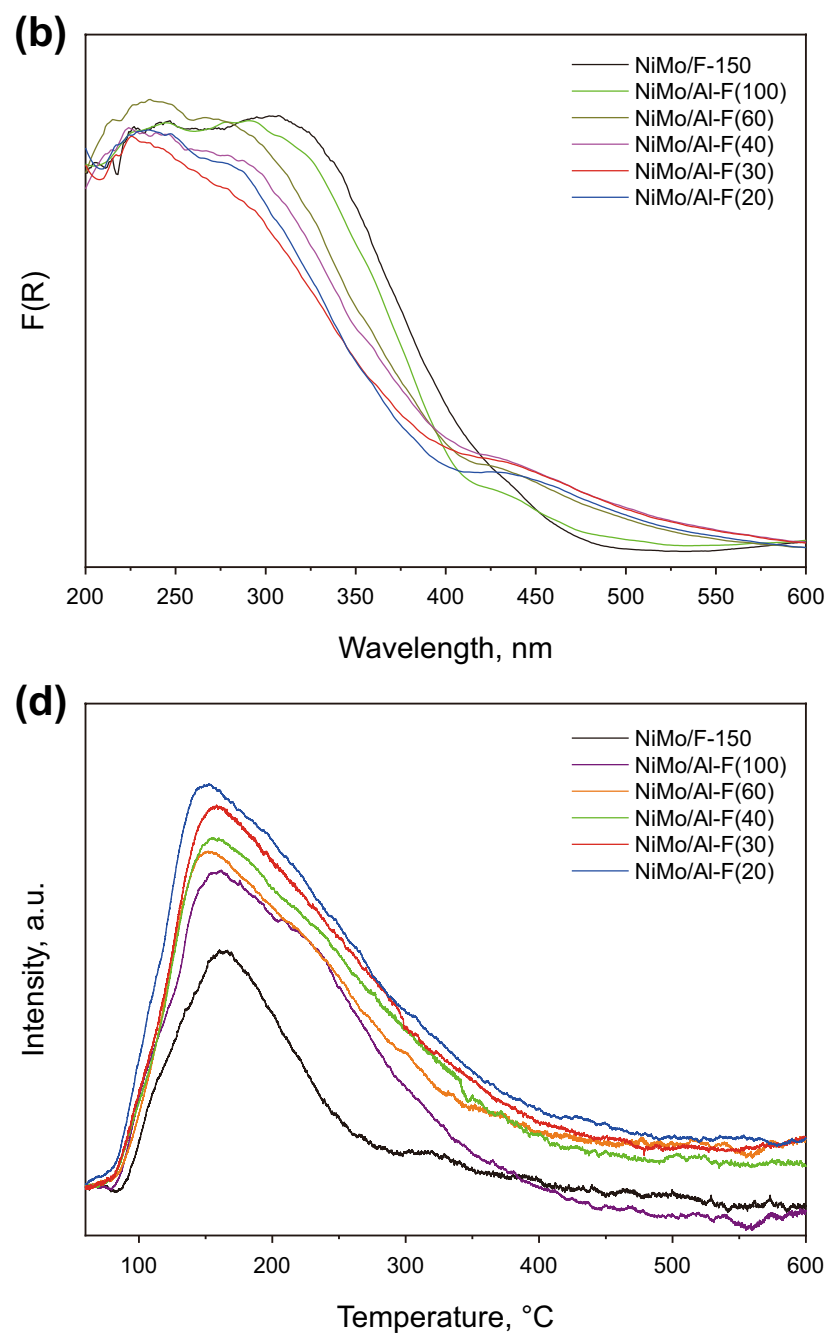

Fig. 6 XRD patterns (a), UV-Vis DRS spectra (b), $\mathrm{H}_{2}$-TPR (c) and $\mathrm{NH}_{3}$-TPD profiles (d) of the catalysts: NiMo/F-150 (a), NiMo/Al-F(100) (b), NiMo/Al-F(60) (c), NiMo/Al-F(40) (d), NiMo/Al-F(30) (e) and NiMo/Al-F(20) (f) 
The pyridine adsorption IR spectroscopy measurements were taken after evacuation at 200 and $350{ }^{\circ} \mathrm{C}$ in the wave number range $1600-400 \mathrm{~cm}^{-1}$, and the results are shown in Fig. S5. The peak at $1450 \mathrm{~cm}^{-1}$ is assigned to pyridine adsorbed onto $L$ acid sites and the peak at $1540 \mathrm{~cm}^{-1}$ is ascribed to pyridine adsorbed onto $B$ acid sites, while the peak at $1490 \mathrm{~cm}^{-1}$ is attributed to pyridine adsorbed onto both $B$ and $L$ acid sites (Kataoka and Dumesic 1988). An attempt has also been made to quantitatively estimate the number of $B$ and $L$ acid sites for the five catalysts using pyridine adsorption followed by degassing at 200 and $350{ }^{\circ} \mathrm{C}$, corresponding to the total and medium/strong acid sites, respectively. The acid strength distributions and acid quantities of NiMo/F-150 and NiMo/Al-F $(x)$ catalysts are listed in Table 4. After degassing at $200{ }^{\circ} \mathrm{C}$, the amount of $B$ acid sites of the NiMo/Al-F(100) catalyst is about 3.6 times as high as that of the NiMo/F-150 catalyst, while this difference is slightly smaller (about two times) for the amounts of medium and strong acid sites after degassing at $350{ }^{\circ} \mathrm{C}$, and the amounts of $B$ acid sites of the NiMo/Al$\mathrm{F}(x)$ catalysts all increase with increasing $\mathrm{Al}$ content. The $L$ acid sites of the NiMo catalysts present a similar changing trend with $\mathrm{B}$ acid sites. In addition, the $B / L$ ratio of the NiMo catalysts gradually increases and then decreases with the increase in the $\mathrm{Al}$ loading amount and peaks at the $\mathrm{Si} / \mathrm{Al}$ molar ratio of 30 .

The Mo $3 d$ and Ni $2 p$ XPS spectra of the sulfided NiMo catalysts accompanied by their deconvolutions are displayed in Figs. S6 and S7. The corresponding parameters of the different contributions Mo $3 d$ and Ni $2 p$ are concluded in Table 5. It is shown that the values of $\mathrm{Mo}_{\text {sulfidation }}$, S/Mo and $\mathrm{Ni} /(\mathrm{Ni}+\mathrm{Mo})$ of Al-incorporated catalysts are higher than that of the NiMo/F-150 catalyst and they all increase with the decrease in the $\mathrm{Si} / \mathrm{Al}$ molar ratio from 100 to 30, indicating the incorporation of an appropriate amount of $\mathrm{Al}$ can improve the dispersion of Mo and Ni species. However, the above three values of the NiMo/Al-F(20) catalyst decrease in comparison with the NiMo/Al-F(30) catalyst, which could be attributed to the appearance of aluminum molybdate and the decrease in the surface area.

The HRTEM images of the sulfided catalysts $\mathrm{NiMo} /$ Al-F(100) and NiMo/Al-F(40) are shown in Fig. S8, and it can be observed that the morphology of $\mathrm{MoS}_{2}$ crystallites changes depending on the support. As described previously, in the pure silica F-150 supported catalyst, $\mathrm{MoS}_{2}$ crystallites with length between 10 and $15 \mathrm{~nm}$ and stacking layers from five to twelve are found (Fig. 4c). Al incorporation in $\mathrm{F}-150$ as support results in a better dispersion of $\mathrm{MoS}_{2}$ phase.

\subsection{HDS catalytic activity}

Catalytic behaviors of the NiMo/F- $(T)$ catalysts were evaluated in HDS of DBT at $360^{\circ} \mathrm{C}$, and the results are shown in Fig. 7. As the hydrothermal temperature increases, the corresponding catalyst desulfurization rate increases first and then decreases, and NiMo/F-150 shows the maximum HDS rate of $94.5 \%$. Although the supports (F-100 and F-130) prepared at lower hydrothermal temperature have larger specific surface area and the corresponding catalysts have the highest proportion of sulfidation degree and NiMoS active phase, the obtained support entrance sizes are too small and restrict

Table 5 XPS parameters of the different contributions Mo $3 d$ and Ni $2 p$ obtained for sulfided $\mathrm{NiMo} / \mathrm{Al}-\mathrm{F}(x)$ catalysts

\begin{tabular}{llll}
\hline Catalysts & $\mathrm{Mo}_{\text {sulfidation }}, \%$ & $\mathrm{~S} / \mathrm{Mo}$ & $\mathrm{Ni} /(\mathrm{Ni}+\mathrm{Mo})$ \\
\hline NiMo/Al-F(100) & 54.6 & 1.6 & 0.27 \\
NiMo/Al-F(60) & 58.9 & 1.8 & 0.28 \\
NiMo/Al-F(40) & 61.4 & 2.0 & 0.28 \\
NiMo/Al-F(30) & 63.4 & 2.1 & 0.30 \\
NiMo/Al-F(20) & 57.1 & 1.7 & 0.27 \\
\hline
\end{tabular}

Table 4 Surface acidity of the catalysts NiMo/F-150 and NiMo/Al-F $(x)$ determined by Py FT-IR

\begin{tabular}{|c|c|c|c|c|c|c|}
\hline \multirow[t]{2}{*}{ Catalyst } & \multicolumn{2}{|c|}{$B, \mu \mathrm{mol} / \mathrm{g}^{\mathrm{a}}$} & \multicolumn{2}{|c|}{$L, \mu \mathrm{mol} / \mathrm{g}^{\mathrm{a}}$} & \multicolumn{2}{|l|}{$B / L$} \\
\hline & $200^{\mathrm{b}}$ & $350^{\mathrm{b}}$ & 200 & 350 & 200 & 350 \\
\hline NiMo/F-150 & 5 & 1 & 84 & 26 & 0.06 & 0.04 \\
\hline NiMo/Al-F(100) & 18 & 2 & 111 & 34 & 0.16 & 0.06 \\
\hline NiMo/Al-F(60) & 37 & 4 & 136 & 39 & 0.27 & 0.10 \\
\hline NiMo/Al-F(40) & 50 & 6 & 170 & 50 & 0.29 & 0.12 \\
\hline NiMo/Al-F(30) & 56 & 9 & 187 & 69 & 0.30 & 0.13 \\
\hline NiMo/Al-F(20) & 54 & 9 & 241 & 99 & 0.22 & 0.09 \\
\hline
\end{tabular}

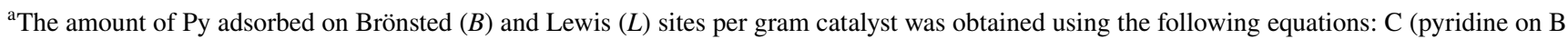
sites $)=1.88 \mathrm{IA}(\mathrm{B}) R^{2} / \mathrm{W} ; C$ (pyridine on $L$ sites) $=1.42 \mathrm{IA}(\mathrm{L}) R^{2} / \mathrm{W}$, where $C=$ concentration $(\mathrm{mmol} / \mathrm{g}$ catalyst), IA(B, L) $=$ integrated absorbance of $B$ or $L$ band $\left(\mathrm{cm}^{-1}\right), R=$ radius of catalyst disk $(\mathrm{cm}), \mathrm{W}=$ weight of disk $(\mathrm{mg})$

${ }^{\mathrm{b}}$ Temperature of Py desorption $\left({ }^{\circ} \mathrm{C}\right)$ 
the diffusion of materials. In addition, the small entrance sizes of the catalysts obtained at a lower hydrothermal temperature not only limit the diffusion of reactants and product molecules during the reaction (Table S1), but also prevent the sufficient contact between the active phases and the reactants, thereby reducing the HDS performance. As the hydrothermal temperature increases, the cavity and entrance sizes of the support are increased significantly, and the desulfurization rate of the catalyst $\mathrm{NiMo} / \mathrm{F}-150$ reached the maximum. This is because the larger pore sizes can facilitate the rapid transport of the materials and promote the reactants to contact sufficiently with the active phases. Further increasing the hydrothermal temperature, the specific surface area of prepared materials decreases significantly and the diffusion resistance is small, resulting in a deterioration of the dispersion of the active component so that some of the active phases do not function during the reaction. In addition, the proportion of the sulfidation degree of the catalyst and the active phases of NiMoS are also greatly reduced, which seriously affect the HDS reaction.

The values of the HDS ratio (performed at $340{ }^{\circ} \mathrm{C}$ ) and pseudo-first-order rate constant $k_{\mathrm{HDS}}$ for the catalysts with

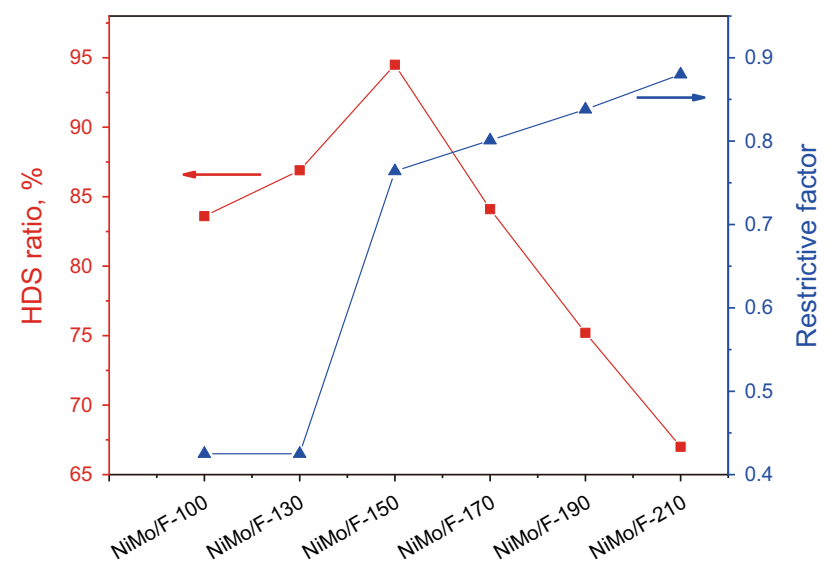

Fig. 7 HDS ratios and restrictive factors of the catalysts. The HDS reaction was performed at $360{ }^{\circ} \mathrm{C}$
$\mathrm{Al}$ incorporation are summarized in Table 6. It is shown that all the catalysts exhibit higher catalytic activity than that without $\mathrm{Al}$. The HDS ratio increases when $\mathrm{Si} / \mathrm{Al}$ molar ratio decreases from 100 to 30 . NiMo/Al-F(30) catalyst possesses the highest HDS ratio (97.8\%) and $k_{\mathrm{HDS}}(1.27)$ values, which are about 1.25 times and 3.43 times as high as NiMo/F-150 catalyst (HDS ratio of $78.1 \%$ and $k_{\mathrm{HDS}}$ of 0.37 ), respectively. Further increase in Al loading (Si/Al molar ratio of 20) leads to a decrease in the catalytic activity, and the obtained HDS ratio and $k_{\mathrm{HDS}}$ are $88.7 \%$ and 0.81 for NiMo/Al-F(20), respectively.

HDS of DBT can be realized through two parallel reaction routes (as shown in Fig. S9). One is the direct desulfurization route (DDS) to yield biphenyl (BP) through the hydrogenolysis of $\mathrm{C}-\mathrm{S}$ bonds and then slowly generate cyclohexylbenzene (CHB) by hydrogenation, which can be negligible. The other one is the hydrogenation pathway (HYD) to produce tetrahydrodibenzothiophene (THDBT) and hexahydrodibenzothiophene (HHDBT) intermediates first and then CHB through the hydrogenation of the aromatic rings of DBT molecule. To compare the contributions of the DDS and HYD pathways to the overall HDS activity of the five prepared catalysts, the HYD/DDS selectivity is calculated by dividing the productivity of CHB, THDBT and HHDBT by the yield of BP at the similar DBT conversion (about 50\%), and the results are presented in Table 6 (Pena et al. 2014; Klimova et al. 2009). It is clearly seen that the HDS of DBT proceeds predominantly through the DDS route and the HYD/DDS ratio is positively correlated with the specific activities of the catalysts, indicating that the total HDS activities of DBT of the sulfided NiMo/F-150 and NiMo/Al-F $(x)$ catalysts depend mostly on the conversion rate to BP (Nava et al. 2007). The HYD/DDS ratios follow the order: NiMo/F-150< NiMo/Al-F(100) $<\mathrm{NiMo} /$ $\mathrm{Al}-\mathrm{F}(20)<\mathrm{NiMo} / \mathrm{Al}-\mathrm{F}(60)<\mathrm{NiMo} / \mathrm{Al}-\mathrm{F}(40)<\mathrm{NiMo} /$ $\mathrm{Al}-\mathrm{F}(30)$. The HYD/DDS ratios of the Al-incorporated catalysts are higher than that of the NiMo/F-150 catalyst, indicating that the desulfurization of DBT over the Al-modified supported catalysts promotes the HYD route more than the

Table 6 HDS activity and product selectivity of the catalysts NiMo/F-150 and NiMo/Al-F $(x)$

\begin{tabular}{|c|c|c|c|c|c|c|}
\hline \multirow[t]{2}{*}{ Catalyst } & \multirow[t]{2}{*}{ HDS ratio, $\%$} & \multirow{2}{*}{$\begin{array}{l}K_{\mathrm{HDS}}, 10^{-6} \\
\mathrm{~mol} / \mathrm{g} \mathrm{s}\end{array}$} & \multicolumn{3}{|c|}{ HYD ratio } & \multirow{2}{*}{$\begin{array}{l}\text { HYD/ } \\
\text { DDS } \\
\text { ratio }^{\text {a }}\end{array}$} \\
\hline & & & $\mathrm{BP}$ & THDBT + HHDBT & $\mathrm{CHB}$ & \\
\hline NiMo/F-150 & 78.1 & 0.50 & 85.3 & 4.3 & 10.4 & 0.17 \\
\hline NiMo/Al-F(100) & 85.7 & 0.65 & 83.1 & 7.3 & 9.6 & 0.20 \\
\hline NiMo/Al-F(60) & 90.8 & 0.79 & 79.8 & 12.1 & 8.1 & 0.25 \\
\hline NiMo/Al-F(40) & 95.2 & 1.01 & 75.6 & 18.2 & 6.2 & 0.32 \\
\hline NiMo/Al-F(30) & 97.8 & 1.27 & 73.5 & 20.8 & 5.7 & 0.36 \\
\hline NiMo/Al-F(20) & 88.7 & 0.71 & 82.0 & 9.6 & 8.4 & 0.22 \\
\hline
\end{tabular}

${ }^{\mathrm{a}}$ Obtained by dividing DDS by HYD, HYD $=\mathrm{CHB}+\mathrm{THDBT}+\mathrm{HHDBT}$, DDS $=\mathrm{BP}$. The HDS reaction was performed at $340{ }^{\circ} \mathrm{C}$ 
pure silica supported catalyst. The effect of $\mathrm{Al}$ incorporation can be attributed to the structure and specific electronic properties of the active phases formed on the Al-modified support. The acceleration of the HYD pathway must be associated with a good dispersion of the active phase from the above analysis results. Moreover, the amount of B acid sites has also some relationship to HYD route. The NiMo/ Al-F(30) catalyst presents the highest HYD/DDS ratio, while the ratio decreases in the NiMo/Al-F(20) catalyst which may be explained by the fact that the excessive Al loading causes a decrease in surface area and the appearance of $\mathrm{Al}_{2}\left(\mathrm{MoO}_{4}\right)_{3}$, leading to a decrease in the amount of active phases.

$\mathrm{NiMo} / \mathrm{Al}-\mathrm{F}(30)$, the best desulfurization catalyst, was evaluated with the model compound 4,6-DMDBT at the reaction temperature of $340{ }^{\circ} \mathrm{C}$, the weight hourly space velocity (WHSV) of $15 \mathrm{l} / \mathrm{h}$, the $\mathrm{H}_{2} /$ oil volume ratio of 300 and the pressure of 4.0 MPa. We speculated the reaction path (Fig. 8) of 4,6-DMDBT according to the product distribution analyzed using GC-MS. It presents three reaction paths of DDS, HYD and isomerization (ISO) in which the first two paths were reported in most of the studies (Zhang et al. 2017). In the DDS pathway, 3,3'-dimethylbiphenyl (3,3'-DMBP) is obtained by hydrogenolysis of 4,6-DMDBT molecules directly. In the HYD pathway, a benzene ring is first hydrogenated to form 4,6-tetrahydrodimethyldibenzothiophene (4,6-THDMDBT) or 4,6-hexahydrodimethyldibenzothiophene (4,6-HHDMDBT), and after desulfurization, 3,3'-dimethylcyclohexenebenzene (3,3'-DMCHEB) and 3,3'-dimethylbicyclohexane (3, $3^{\prime}$-DMBCH) are formed. Partially isomerized products are produced ascribing to the increase in B acid content after Al modification. It promotes methyl transfer and produces 3,7-dimethyldibenzothiophene (3,7-DMDBT) and 2,7-dimethyldibenzo thiophene (2,8-DMDBT). Afterward, 4,4'-dimethylbiphenyl (4,4'-DMBP) and 4,5'-dimethylbiphenyl (4,5'-DMBP) are formed after desulfurization. Further hydrogenation generates a small amount of 4,4'-dimethylbicyclohexane $\left(4,4^{\prime}\right.$ $\mathrm{DMBCH})$ and 4,5'-dimethylbicyclohexane (4,5'-DMBCH). The specific contents are shown in Fig. 8. It is known that the 4,6-DMDBT molecule is difficult to be desulfurized because of the strong steric hindrance which makes the active sites difficult to directly contact with sulfur atoms. But herein, the methyl transfer occurring in the isomerization can greatly reduce this steric effect, and additionally, the sizes of the entrance and cavity of the NiMo/Al-F(30) catalyst are large, which reduces the diffusion resistance of the 4,6-DMDBT molecule in the reaction and is expected to be beneficial for the hydrodesulfurization.

\section{Conclusion}

A series of NiMo/FDU-12 catalysts have been comprehensively characterized to explore the effects of the pore size, mesostructure and aluminum modification on the $\mathrm{MoS}_{2}$ morphology and their catalytic performance for HDS. The support structures transform from $3 \mathrm{D}$ to homologous $2 \mathrm{D}$ straight channel with the increase in the hydrothermal temperature, while the $\mathrm{MoS}_{2}$ morphology alters from straight bar to semibending arc then to closed shell and finally to straight bar on the corresponding catalysts. It is found that $\mathrm{MoS}_{2}$ with bended morphology has more active sites with high activity. Thus, F-150 support possessing appropriate pore diameter, 3D structure and curved $\mathrm{MoS}_{2}$ exhibits the

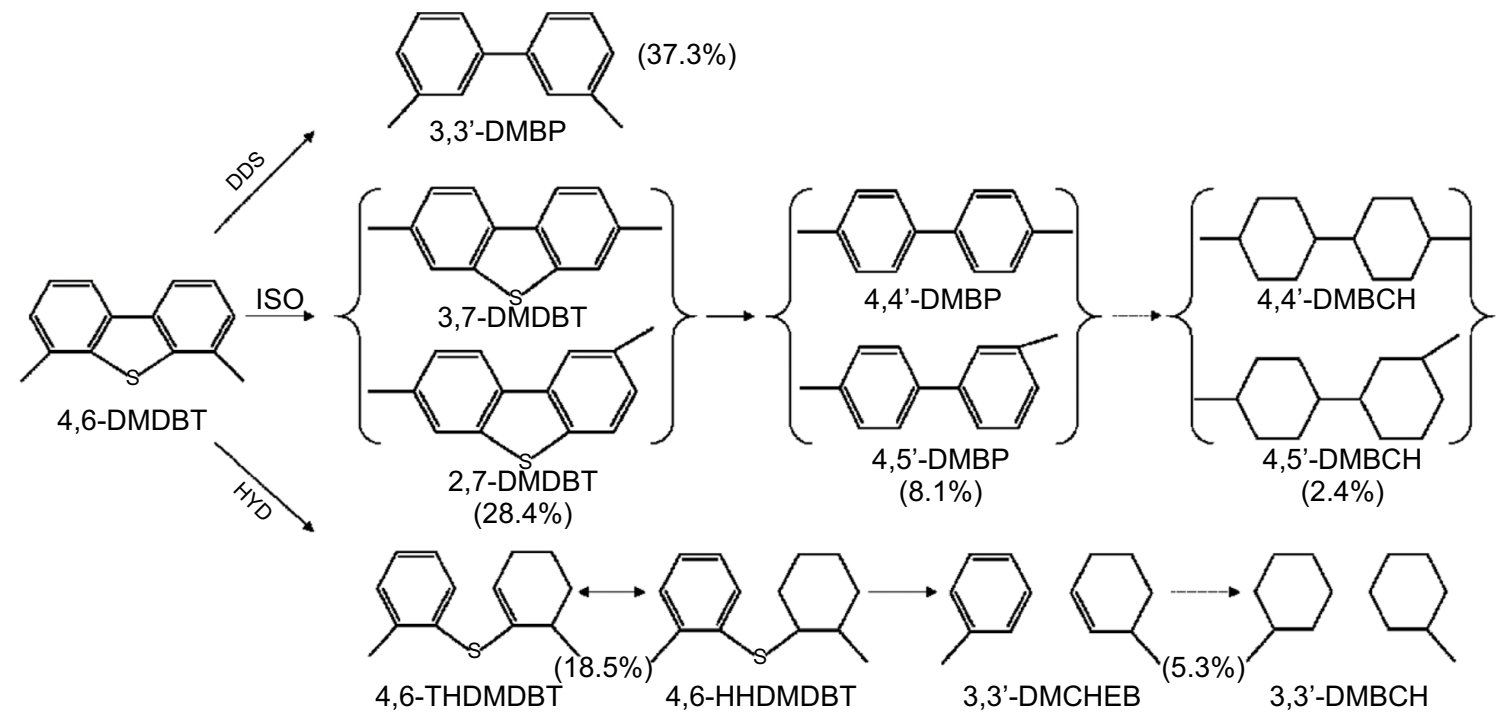

Fig. 8 Reaction pathway of 4,6-DMDBT and product compositions for 4,6-DMDBT HDS on NiMo/Al-F(30) catalyst 
best HDS performance. The incorporation of aluminum facilitates the dispersion of Mo and Ni species. With an appropriate $\mathrm{Al}$ incorporation, $\mathrm{Mo}$ and $\mathrm{Ni}$ species are easier to be sulfided to form $\mathrm{MoS}_{2}$ and NiMoS phases. HDS tests show that the catalytic activities gradually increase and then decrease with the increase in the $\mathrm{Al}$ content, and the $\mathrm{NiMo} /$ Al-F(30) catalyst exhibits the highest HDS efficiency due to its relatively high surface area, good dispersion of the active phases and high acid content. Our study demonstrates that the support structure plays an important role on active sites morphology and HDS performance, which might help to develop highly active HDS catalysts for macromolecular sulfur compounds.

Acknowledgements This work was financially supported by the National Natural Science Foundation of China (Grant Nos. 21776048, 21576290, 21106182) and the Natural Science Foundation of Fujian Province (2018J06002).

Open Access This article is licensed under a Creative Commons Attribution 4.0 International License, which permits use, sharing, adaptation, distribution and reproduction in any medium or format, as long as you give appropriate credit to the original author(s) and the source, provide a link to the Creative Commons licence, and indicate if changes were made. The images or other third party material in this article are included in the article's Creative Commons licence, unless indicated otherwise in a credit line to the material. If material is not included in the article's Creative Commons licence and your intended use is not permitted by statutory regulation or exceeds the permitted use, you will need to obtain permission directly from the copyright holder. To view a copy of this licence, visit http://creativecommons.org/licenses/by/4.0/.

\section{References}

Cao Z, Duan A, Zhao Z, et al. A simple two-step method to synthesize the well-ordered mesoporous composite Ti-FDU-12 and its application in the hydrodesulfurization of DBT and 4,6-DMDBT. J Mater Chem A. 2014;2(46):19738-49. https://doi.org/10.1039/ c4ta03691c.

Dong L, Miao G, Ren X, et al. Desulfurization kinetics and regeneration of silica gel-supported $\mathrm{TiO}_{2}$ extrudates for reactive adsorptive desulfurization of real diesel. Ind Eng Chem Res. 2020;59(21):10130-41. https://doi.org/10.1021/acs.iecr.0c00942.

Du P, Zheng P, Song S, et al. Synthesis of a novel micro/mesoporous composite material beta-FDU-12 and its hydro-upgrading performance for FCC gasoline. RSC Adv. 2016;6(2):1018-26. https:// doi.org/10.1039/c5ra19731g.

Escobar J, Barrera MC, Toledo JA, et al. Effect of ethyleneglycol addition on the properties of $\mathrm{P}$-doped $\mathrm{NiMo} / \mathrm{Al}_{2} \mathrm{O}_{3}$ HDS catalysts: part I. Materials preparation and characterization. Appl Catal B Environ. 2009;88(3-4):564-75. https://doi.org/10.1016/j.apcat b.2008.10.005.

Gao Y, Han W, Long X, et al. Preparation of hydrodesulfurization catalysts using $\mathrm{MoS}_{3}$ nanoparticles as a precursor. Appl Catal B Environ. 2018;224:330-40. https://doi.org/10.1016/j.apcat b.2017.10.046.

Gutierrez-Alejandre A, Laurrabaquio-Rosas G, Ramirez J, et al. On the role of triethylene glycol in the preparation of highly active $\mathrm{Ni}-$ $\mathrm{Mo} / \mathrm{Al}_{2} \mathrm{O}_{3}$ hydrodesulfurization catalysts: a spectroscopic study.
Appl Catal B Environ. 2015;166:560-7. https://doi.org/10.1016/j. apcatb.2014.11.039.

Han W, Yuan P, Fan Y, et al. Preparation of supported hydrodesulfurization catalysts with enhanced performance using Mo-based inorganic-organic hybrid nanocrystals as a superior precursor. J Mater Chem. 2012;22(48):25340-53. https://doi.org/10.1039/ c2jm34979e.

Hu D, Li YY, Mei JL, et al. High-dispersed Ni-Mo-S active phases within hierarchical pore materials by introducing the cationic protective shell during the impregnation process for hydrodesulfurization. Fuel. 2020. https://doi.org/10.1016/j.fuel.2019.116701.

Jiang W, Zhu K, Li H, et al. Synergistic effect of dual Brønsted acidic deep eutectic solvents for oxidative desulfurization of diesel fuel. Chem Eng J. 2020;394:124831. https://doi.org/10.1016/j. cej.2020.124831.

Kaluza L, Karban J, Gulkova D. Activity and selectivity of Co(Ni) Mo sulfides supported on $\mathrm{MgO}, \mathrm{Al}_{2} \mathrm{O}_{3}, \mathrm{ZrO}_{2}, \mathrm{TiO}_{2}, \mathrm{MCM}-41$ and activated carbon in parallel hydrodeoxygenation of octanoic acid and hydrodesulfurization of 1-benzothiophene. React Kinet Mech Catal. 2019;127(2):887-902. https://doi.org/10.1007/s1114 4-019-01620-x.

Kataoka T, Dumesic JA. Acidity of unsupported and silica-supported vanadia, molybdena, and titania as studied by pyridine adsorption. J Catal. 1988;112(1):66-79. https://doi.org/10.1016/00219517(88)90121-2.

Klimova T, Reyes J, Gutierrez O, et al. Novel bifunctional NiMo/AlSBA-15 catalysts for deep hydrodesulfurization: effect of support Si/Al ratio. Appl Catal A Gen. 2008;335(2):159-71. https://doi. org/10.1016/j.apcata.2007.11.008.

Klimova T, Pena L, Lizama L, et al. Modification of activity and selectivity of NiMo/SBA-15 HDS catalysts by grafting of different metal oxides on the support surface. Ind Eng Chem Res. 2009;48(3):1126-33. https://doi.org/10.1021/ie800626k.

Li Y, Pan D, Yu C, et al. Synthesis and hydrodesulfurization properties of NiW catalyst supported on high-aluminum-content, highly ordered, and hydrothermally stable Al-SBA-15. J Catal. 2012;286:124-36. https://doi.org/10.1016/j.jcat.2011.10.023.

Li X, Zhu H, Liu C, et al. Synthesis, modification, and application of hollow mesoporous carbon submicrospheres for adsorptive desulfurization. Ind Eng Chem Res. 2018a;57(44):15020-30. https ://doi.org/10.1021/acs.iecr.8b02780.

Li Y, Chi K, Zhang H, et al. The influence of hydrothermal crystallization temperature on a novel FDU-12 mesoporous composite assembled by ZSM-5 nanoclusters and its hydrodesulfurization performance for DBT and FCC diesel. Fuel Process Technol. 2018b;180:56-66. https://doi.org/10.1016/j.fuproc.2018.08.010.

$\mathrm{Li} \mathrm{H,} \mathrm{Li} \mathrm{Y,} \mathrm{Hu} \mathrm{D,} \mathrm{et} \mathrm{al.} \mathrm{Effect} \mathrm{of} \mathrm{inorganic} \mathrm{salts} \mathrm{on} \mathrm{beta-FDU-12} \mathrm{micro-/}$ mesoporous materials with the applications in dibenzothiphene hydrodesulfurization. Ind Eng Chem Res. 2019;58(27):11831-40. https://doi.org/10.1021/acs.iecr.9b01649.

Liu C, Yuan P, Cui C. The pore confinement effect of FDU-12 mesochannels on $\mathrm{MoS}_{2}$ active phases and their hydrodesulfurization performance. J Nanomaterial. 2016. https://doi. org/10.1155/2016/5208027.

Liu B, Liu L, Wang Z, et al. Effect of hydrogen spillover in selective hydrodesulfurization of FCC gasoline over the CoMo catalyst. Catal Today. 2017;282:214-21. https://doi.org/10.1016/j.catto d.2016.08.020.

Liu C, Yuan P, Duan A, et al. Monodispersed dendritic mesoporous silica/carbon nanospheres with enhanced active site accessibility for selective adsorptive desulfurization. J Mater Sci. 2019;54(11):8148-62. https://doi.org/10.1007/s10853-019-03461 -4 .

Mayanovic RA, Yan H, Brandt AD, et al. Mechanical and hydrothermal stability of mesoporous materials at extreme conditions. Microp 
Mesop Mater. 2014;195:161-6. https://doi.org/10.1016/j.micro meso.2014.04.027.

Mendez FJ, Franco-Lopez OE, Bokhimi X, et al. Dibenzothiophene hydrodesulfurization with NiMo and CoMo catalysts supported on niobium-modified MCM-41. Appl Catal B Environ. 2017;219:479-91. https://doi.org/10.1016/j.apcatb.2017.07.079.

Meng Q, Du P, Wang B, et al. Synthesis of zirconium modified FDU12 by different methods and its application in dibenzothiophene hydrodesulfurization. RSC Adv. 2018;8(48):27565-73. https:// doi.org/10.1039/c8ra05032e.

Meng Q, Peng D, Duan AJ, et al. Trimetallic catalyst supported zirconium-modified three-dimensional mesoporous silica material and its hydrodesulfurization performance of dibenzothiophene and 4,6-dimethydibenzothiophene. Ind Eng Chem Res. 2020;59(2):654-67. https://doi.org/10.1021/acs.iecr.9b04647.

Merida-Robles J, Rodriguez-Castellon E, Jimenez-Lopez A. Characterization of Ni, Mo and Ni-Mo catalysts supported on alumina-pillared alpha-zirconium phosphate and reactivity for the thiophene HDS reaction. J Mol Catal A: Chem. 1999;145(1-2):169-81. https ://doi.org/10.1016/s1381-1169(99)00048-5.

Nava R, Ortega RA, Alonso G, et al. CoMo/Ti-SBA-15 catalysts for dibenzothiophene desulfurization. Catal Today. 2007;127(14):70-84. https://doi.org/10.1016/j.cattod.2007.02.034.

Ninh TKT, Massin L, Laurenti D, et al. A new approach in the evaluation of the support effect for NiMo hydrodesulfurization catalysts. Appl Catal A Gen. 2011;407(1-2):29-39. https://doi. org/10.1016/j.apcata.2011.08.019.

Palcheva R, Kaluza L, Dimitrov L, et al. NiMo catalysts supported on the Nb modified mesoporous SBA-15 and HMS: effect of thioglycolic acid addition on HDS. Appl Catal A Gen. 2016;520:24-34. https://doi.org/10.1016/j.apcata.2016.04.008.

Pena L, Valencia D, Klimova T. CoMo/SBA-15 catalysts prepared with EDTA and citric acid and their performance in hydrodesulfurization of dibenzothiophene. Appl Catal B Environ. 2014;147:87987. https://doi.org/10.1016/j.apcatb.2013.10.019.

Qu LL, Zhang WP, Kooyman PJ, et al. MAS NMR, TPR, and TEM studies of the interaction of NiMo with alumina and silica-alumina supports. J Catal. 2003;215(1):7-13. https://doi.org/10.1016/ s0021-9517(02)00181-1.

Rajendran A, Cui TY, Fan HX, et al. A comprehensive review on oxidative desulfurization catalysts targeting clean energy and environment. J Mater Chem A. 2020;8(5):2246-85. https://doi. org/10.1039/c9ta12555h.

Song S, Zhou X, Duan A, et al. Synthesis of mesoporous silica material with ultra-large pore sizes and the HDS performance of dibenzothiophene. Microp Mesop Mater. 2016;226:510-21. https://doi. org/10.1016/j.micromeso.2016.01.034.

Soni K, Mouli KC, Dalai AK, et al. Influence of frame connectivity of SBA-15 and KIT-6 supported NiMo catalysts for hydrotreating of gas oil. Catal Lett. 2010;136(1-2):116-25. https://doi. org/10.1007/s10562-010-0317-0.

Thanh Tung N, Qian EW. Synthesis of mesoporous Ti-inserted SBA15 and $\mathrm{CoMo} / \mathrm{Ti}-\mathrm{SBA}-15$ catalyst for hydrodesulfurization and hydrodearomatization. Microp Mesop Mater. 2018;265:1-7. https ://doi.org/10.1016/j.micromeso.2018.01.026.

Vutolkina AV, Glotov AP, Zanina AV, et al. Mesoporous Al-HMS and Al-MCM-41 supported Ni-Mo sulfide catalysts for HYD and HDS via in situ hydrogen generation through a WGSR. Catal Today. 2019;329:156-66. https://doi.org/10.1016/j.catto d.2018.11.030.

Wang AJ, Wang Y, Kabe T, et al. Hydrodesulfurization of dibenzothiophene over siliceous MCM-41-supported catalysts-II. Sulfided Ni-Mo catalysts. J Catal. 2002;210(2):319-27. https:// doi.org/10.1006/jcat.2002.3674.
Wang AJ, Ruan LF, Teng Y, et al. Hydrodesulfurization of dibenzothiophene over siliceous MCM-41-supported nickel phosphide catalysts. J Catal. 2005;229(2):314-21. https://doi.org/10.1016/j. jcat.2004.09.022

Wang X, Du P, Chi K, et al. Synthesis of NiMo catalysts supported on mesoporous silica FDU-12 with different morphologies and their catalytic performance of DST HDS. Catal Today. 2017;291:14652. https://doi.org/10.1016/j.cattod.2016.10.035.

Wang X, Mei J, Zhao Z, et al. Controllable synthesis of spherical AlSBA-16 mesoporous materials with different crystal sizes and its high isomerization performance for hydrodesulfurization of dibenzothiophene and 4,6-dimethyldibenzothiophene. Ind Eng Chem Res. 2018;57(7):2498-507. https://doi.org/10.1021/acs. iecr.8b00109.

Weber RS. Effect of local-structure on the UV-visible absorption edges of molybdenum bride clusters and supported molybdenum oxides. J Catal. 1995;151(2):470-4. https://doi.org/10.1006/ jcat.1995.1052.

Wei Y, Zhang M, Wu P, et al. Tailoring electronic properties of porphyrin manganese on boron nitride for enhancing aerobic oxidative desulfurization at room temperature. ACS Sustain Chem Eng. 2020;8(2):1015-22. https://doi.org/10.1021/acssuschem eng.9b05728.

Wu L, Ye F, Lei D, et al. Regeneration of AgXO@SBA-15 for reactive adsorptive desulfurization of fuel. Pet Sci. 2018a;15(4):857-69. https://doi.org/10.1007/s12182-018-0264-8.

Wu Q, Li Y, Hou Z, et al. Synthesis and characterization of betaFDU-12 and the hydrodesulfurization performance of FCC gasoline and diesel. Fuel Process Technol. 2018b;172:55-64. https:// doi.org/10.1016/j.fuproc.2017.12.003.

Wu P, Wu Y, Chen L, et al. Boosting aerobic oxidative desulfurization performance in fuel oil via strong metal-edge interactions between Pt and h-BN. Chem Eng J. 2020;380:122526. https://doi. org/10.1016/j.cej.2019.122526.

Yang J, Zhou L, Zhang J, et al. Confinement of chemisorbed phosphates in a controlled nanospace with three-dimensional mesostructures. Chem Eur J. 2013;19(18):5578-85. https://doi. org/10.1002/chem.201300273.

Yu T, Zhang H, Yan X, et al. Pore structures of ordered large cage-type mesoporous silica FDU-12s. J Phys Chem B. 2006;110(43):21467-72. https://doi.org/10.1021/jp064534j.

Yuan P, Liu J, Li Y, et al. Effect of pore diameter and structure of mesoporous sieve supported catalysts on hydrodesulfurization performance. Chem Eng Sci. 2014;111:381-9. https://doi. org/10.1016/j.ces.2014.03.006.

Zhang H, Han L, Duan A, et al. Synthesis of micro-mesoporous materials ZSM-5/FDU-12 and the performance of dibenzothiophene hydrodesulfurization. RSC Adv. 2017;7(45):28038-47. https:// doi.org/10.1039/c7ra03679e.

Zhang Y, Zhou KD, Zhang LF, et al. Synthesis of mesoporous gamma$\mathrm{Al}_{2} \mathrm{O}_{3}$ by using cellulose nanofiber as template for hydrodesulfurization of dibenzothiophene. Fuel. 2019;253:431-40. https://doi. org/10.1016/j.fuel.2019.05.021.

Zhang M, Liu J, Li H, et al. Tuning the electrophilicity of vanadiumsubstituted polyoxometalate based ionic liquids for high-efficiency aerobic oxidative desulfurization. Appl Catal B Environ. 2020;271:118936. https://doi.org/10.1016/j.apcatb.2020.118936.

Zhou WW, Yang L, Liu L, et al. Synthesis of novel NiMo catalysts supported on highly ordered $\mathrm{TiO}_{2}-\mathrm{Al}_{2} \mathrm{O}_{3}$ composites and their superior catalytic performance for 4,6-dimethyldibenzothiophene hydrodesulfurization. Appl Catal B Environ. 2020. https://doi. org/10.1016/j.apcatb.2019.118428. 